\title{
Thermal modelling and experimental assessment of the dependence of PV module temperature on wind velocity and direction, module orientation and inclination
}

\author{
E. Kaplani*1, S. Kaplanis ${ }^{2}$ \\ Mechanical Engineering Department, Technological Educational Institute of Patras, \\ Meg. Alexandrou 1, 26334 Patra, Greece \\ email addresses: ${ }^{1}$ ekaplani@teipat.gr, ${ }^{2}$ kaplanis@teipat.gr \\ * Corresponding Author
}

\begin{abstract}
A theoretical and experimental analysis of PV module temperature under various environmental conditions is presented in relation to module inclination, wind velocity and direction. The present experimental study, makes use of hourly PV temperature data collected from a double-axis suntracking PV system and environmental parameters monitored for a period of one year. The $f$ coefficient which relates the PV module temperature with the intensity of the global solar radiation on the PV plane and the ambient temperature, is assessed in relation to the angle of PV inclination, the wind velocity and the angle of incidence of the wind stream on the PV surface, either front or back. The $f$ coefficient is evaluated both experimentally and theoretically through thermal modelling based on the energy balance equation. The simulation model developed in this study considers heat convection by natural and air forced flow, the flow pattern either laminar or turbulent, the relative geometry of the PV module with respect to the wind direction, and the radiated heat by the PV module. Various expressions for the forced heat convection coefficient available in the literature are tested within the thermal model with reference to the windward and leeward side of the PV module, and their applicability to PV thermal analysis is experimentally assessed in terms of the agreement shown with measured data. The values of the $f$ coefficient provided by the simulation model lie very close to the experimental data for the entire range of PV inclination angles, wind velocities and wind directions tested.
\end{abstract}

Keywords: photovoltaic temperature, inclination, wind velocity and direction, thermal modelling

\section{Nomenclature}

\section{Gr, Grashof number}

$I_{T}$, global solar radiation intensity on the surface of the PV module $\left(\mathrm{W} / \mathrm{m}^{2}\right)$

$L$, length of the PV module in the direction of the natural air flow along its front or back side, or as otherwise stated in the text $(\mathrm{m})$

$N u_{f}, N u_{b}$ the Nusselt number of the air flow in the front and back side of the PV module, respectively Pr, Prandtl number

$R a$, Rayleigh number, $R a=G r \cdot P r$

$R e$, Reynolds number

$T_{p v}, \mathrm{PV}$ module temperature (K)

$T_{a}$, ambient temperature (K)

$T_{f}$, film temperature of the air boundary layer at the PV module side front or back (K)

$T_{g r}$, ground surface temperature (K)

$T_{s}$, sky temperature (K)

$U_{L, f}, U_{L, b}$ heat losses coefficient due to convection and IR radiation at the front and back side of the PV module, respectively $\left(\mathrm{W} / \mathrm{m}^{2} \mathrm{~K}\right)$

$h_{c, g-a}$, heat convection coefficient from PV glass to air $\left(\mathrm{W} / \mathrm{m}^{2} \mathrm{~K}\right)$

$h_{c, b-a}$, heat convection coefficient from PV back surface to air $\left(\mathrm{W} / \mathrm{m}^{2} \mathrm{~K}\right)$ 
$h_{r . g-a}$, radiative heat losses coefficient from PV glass to the environment $\left(\mathrm{W} / \mathrm{m}^{2} \mathrm{~K}\right)$

$h_{r, b-a}$, radiative heat losses coefficient from PV back surface to the environment $\left(\mathrm{W} / \mathrm{m}^{2} \mathrm{~K}\right)$

$\mathrm{k}_{\mathrm{a}}$, thermal conductivity of air $(\mathrm{W} / \mathrm{mK})$

$v_{w}$, wind velocity $(\mathrm{m} / \mathrm{s})$

$\alpha$, thermal diffusivity of the air $\left(\mathrm{m}^{2} / \mathrm{s}\right)$

$\alpha_{w}$, angle of incidence of wind stream on the PV module surface (degrees)

$\beta, P V$ module inclination angle (degrees)

$\gamma_{p v}, \mathrm{PV}$ module orientation angle (degrees)

$\gamma_{\mathrm{w}}$, wind direction (degrees)

$\varepsilon_{g}, \varepsilon_{b}$, emissivity coefficients for the PV glass and the back surface, respectively

$\eta_{p v}, \mathrm{PV}$ module efficiency

$v$, kinematic viscosity of the air $\left(\mathrm{m}^{2} / \mathrm{s}\right)$

\section{Introduction}

In a PV module under solar radiation, a temperature profile is developed above the ambient temperature. The temperature dependence of PV performance has been widely investigated. Experimental and theoretical studies investigating the effect of PV module temperature on its electrical characteristics, performance and efficiency, for PV modules operating in controlled or various environmental conditions, have been reported by Radziemska (2003), King (1996), King et al. (1997) and others.

The PV temperature $T_{p v}$ developed during PV operation, depends on the solar radiation intensity on the module $I_{T}\left(\mathrm{~W} / \mathrm{m}^{2}\right)$, the ambient temperature $T_{a}$, the wind velocity $V_{w}$, the PV module technology and structure, the PV inclination, and the geometry of the PV modules with respect to wind direction. Knowledge of module inclination, orientation and precise environmental conditions is important for the estimation of PV module temperature, and, further, for an accurate estimation of the power to be delivered by the PV generator operating in field conditions. The effect of PV temperature on its power and efficiency is provided through eqs.(1),(2) based on (Mattei et al., 2006; Anderson, 1996).

$P_{m}=P_{m, S T C} \cdot\left[1+\gamma_{P_{m}} \cdot\left(T_{p v}-25^{\circ} \mathrm{C}\right)+\delta \cdot \ln \left(I_{T} / 1000\right)\right] \cdot\left(I_{T} / 1000\right)$

$\eta_{p v}=\eta_{S T C} \cdot\left[1+\gamma_{P_{m}} \cdot\left(T_{p v}-25^{\circ} \mathrm{C}\right)+\delta \cdot \ln \left(I_{T} / 1000\right)\right]$

where $P_{m, S T C}$ and $\eta_{\text {STC }}$ are the PV peak power and efficiency, respectively, at Standard Test Conditions $\left(I_{T}=1000 \mathrm{~W} / \mathrm{m}^{2}\right.$, Air Mass $\left.1.5, T_{P V}=25^{\circ} \mathrm{C}\right) . \gamma_{\mathrm{Pm}}$ is the temperature coefficient for $P_{m}$ and takes values in the region $[-0.4,-0.5] \% /{ }^{\circ} \mathrm{C}$ and is usually provided by the module manufacturer, and $\delta$ the solar irradiance coefficient which is determined equal to 0.085 for single crystalline and 0.11 for polycrystalline modules (Anderson, 1996).

An accurate determination of PV module temperature may, thus, assist the prediction of PV system performance. Theoretical and empirical models giving the PV module temperature as a function of the solar irradiance incident on the PV module, the ambient temperature and the wind speed, have been proposed by Faiman (2008), where $T_{p v}=T_{a}+I_{T} /\left(U_{o}^{\prime}+U_{1}^{\prime} \cdot v_{w}\right)$, and King et al. (2004) where $T_{p v}=T_{a}+I_{T} \cdot \exp \left(a+b \cdot v_{w}\right)$. The advantage of these models is their simplicity. However, for better accuracy they require monitoring the PV temperature and meteorological conditions $\left(T_{a}, I_{T}\right.$, $\left.v_{w}\right)$ for a short period at the specific location of the study in order to adjust the empirical coefficients $(a, b),\left(U_{o}^{\prime}, U_{1}^{\prime}\right)$ for the site and module type. Validation of these models' applicability at different 
climatic regions is presented by Koehl et al. (2011). Thermal aspects related to the development of PV module temperature and the related exchanges with the environment including wind-induced heat transfer have been investigated in several studies, in an attempt to provide an accurate determination of PV module operating temperature. These studies are mainly simulation approaches based on steady-state energy balance equations considering heat transfer by convection natural and forced from the PV sides and long-wave radiation (Mattei et al., 2006; Bardhi et al., 2012; Amy de la Breteque, 2008; Skoplaki et al., 2008). Few studies such as (Notton et al., 2005) have considered in addition heat transfer by conduction between the PV cells and the front and back glasses. Furthermore, non-steady state models to account for fast fluctuating irradiance have also been proposed by Armstrong and Hurley (2010), Notton et al. (2005), Jones and Underwood (2001), considering the thermal mass of the module.

In a PV system operating outdoors the effect of wind velocity on module temperature plays a significant role. However, heat transfer by wind-induced convection has not received appropriate attention. The estimation of air forced heat convection coefficient has been based on theoretical or empirical equations primarily derived for solar collectors, such as those proposed by (McAdams, 1954; Watmuff et al., 1977; Lunde, 1980; Sharples and Charlesworth, 1998; Cole and Sturrock, 1977; Sparrow et al., 1979; Sartori, 2006; Kendoush, 2009). Several of the empirical equations have been applied to photovoltaic energy balance equations for the prediction of PV module temperature (Armstrong and Hurley, 2010; Skoplaki et al., 2008; Mattei et al., 2006; Notton et al., 2005). However, the different effects produced by the various air forced convection coefficient equations or their applicability in the case of photovoltaics has not been particularly studied. The cumbersome task of selecting a particular empirical equation over another is shown in (Mattei et al., 2006; Notton et al., 2005) where a comparison of the estimated PV temperature using energy balance with some of the empirical formulae for the forced heat convection coefficient is presented. Generally, the adoption of any one equation for the air forced convection coefficient in photovoltaic thermal analysis needs to follow a careful study of its applicability. Empirical equations for the air forced convection coefficient produce very different results, as they have been derived based on experimental data produced under different conditions, experimental setups, measurement procedures, tested surfaces, etc, as also discussed in (Sartori, 2006), whereas theoretically derived equations may provide a clear asset. Therefore, a need for a more accurate determination of air forced convection coefficient within energy balance equations using theoretical expressions such as (Sartori, 2006; Kendoush, 2009) and an evaluation of the effect of wind speed and direction with respect to various module inclinations and orientations is identified.

Another aspect that has not received full attention is heat convection when it relates to the different sides of the PV module, front and back. The air forced convection coefficient $h$ formulae were primarily derived for solar collectors and cases of mounted plates on rooftops, and, thus, the initial works considered only the windward side of the surface, with $h$ expressed through the general linear form $h=a \cdot v_{w}+b$, where $v_{w}$ is the wind velocity. Further studies have proposed empirical equations derived both for the windward and leeward side of the surface, with $h$ for the leeward side also expressed by this linear form with smaller $a, b$ parameters (Sharples and Charlesworth, 1998; Cole and Sturrock, 1977). The forced convection coefficient has also been proposed to follow the general power law $h=a \cdot v_{w}^{n}+b$ (Sparrow et al., 1979). Recently, Sartori (2006) has considered the wind direction in the air forced convection expression indirectly through the length of the surface in the wind direction, while Kendoush (2009) has explicitly incorporated the incidence angle in the expression for $h$ in fluids flowing across a flat plate. A review of the various expressions for $h$ that have been proposed in the literature for the different systems and experiments is provided by Palyvos (2008). Given the lack of wind direction measurements, many PV temperature simulation models use only empirical expressions developed for the windward side and multiply it by 2 to 
account for both PV sides, or sum the windward and leeward empirical forced convection coefficients (Mattei et al., 2006) without distinguishing between front and back PV side.

Furthermore, natural convection is highly affected by different module inclination angles, and also forced convection is affected by the combination of module inclination, orientation and wind direction. These aspects have not been particularly addressed in previous thermal models.

The thermal model developed in the present study addresses all the above issues. It makes use of theoretically derived air forced convection coefficient equations proposed in the literature for fluids flowing over flat surfaces, and shows to have a clear advantage over the use of empirical expressions. An approach for the leeward side of the module is also presented. A detailed algorithm for the determination of the natural convection at any PV inclination angle for the front and back side of the PV module, and the forced convection coefficient at any PV inclination, orientation and wind direction for the windward and leeward side of the module, is presented. The effect of wind velocity, wind incidence angle on the PV surface, and PV inclination, on the module temperature are examined both theoretically and experimentally, through coefficient $f$ which relates PV module temperature to ambient temperature and solar radiation intensity on the PV surface, where $T_{p v}=T_{a}+f \cdot I_{T}$. The purpose of the present study is to examine the effect of the aforementioned parameters on coefficient $f$, as this also signifies their effect on module temperature, develop a thermal model to simulate $f$ and validate it via comparison with a wide range of experimental data.

\section{Thermal model}

For a PV module with conversion efficiency $\eta_{p v}$ inclined with respect to horizontal at an angle $\beta$ and with global solar radiation intensity $I_{T}$ incident on the PV plane, a part, $r$, of the solar radiation is reflected from the PV module surface. The remaining part equal to $\left((1-r) \cdot(\tau \alpha)-\eta_{p v}\right) \cdot I_{T} \cdot A_{p v}$ is dissipated into heat, and causes an increase of the PV temperature above the ambient $T_{a}$. ( $\left.\tau \alpha\right)$ is the transmission-absorption coefficient as analyzed in (Bardhi et al., 2012).

In the thermal model the following assumptions are made:

- Reflection losses are considered negligible as the study uses a sun tracking PV system and the angle of incidence of the solar radiation is normal to the PV plane.

- The transmission-absorption coefficient of the module and the emissivity are considered constant, and independent of wavelength.

- The temperature of the PV module is considered uniform.

- Heat transfer by conduction is not considered. The thermal model is expressed in terms of the temperature at the back PV surface, for direct comparison with the experimental results where temperature was actually measured at the back surface of the module. The temperature of the front $\left(T_{p v, f}\right)$ and of the back PV surface $\left(T_{p v, b}\right)$ are considered equal. Note that in fact $T_{p v, f}$ and $T_{p v, b}$ may differ between $0-3^{\circ} \mathrm{C}$. A sensitivity analysis on the introduction of $T_{p v, f}$ equal to $T_{p v, b}$ was carried out and is presented in the Discussion section.

- Clear sky conditions are considered.

- The thermal capacity of the PV module and transient phenomena are neglected. PV temperature fluctuations are mostly caused by clouds and intermittent sunshine, and, thus, since clear sky conditions are considered solar radiation fluctuations are small. Note that a quality check on the experimental data was performed and data that corresponded to fast changing solar radiation at the first/last hour of the day were removed. The effect of fluctuating wind speed is directly passed onto the temperature of the back PV surface with a time constant $\tau<<4$ minutes of the averaging period of the measurements. 
The energy balance equation for steady state conditions and for negligible module reflectance $r$, is provided by eq.(3) and takes into account the solar radiation which reaches the PV module, the power produced, the heat losses due to convection and the IR radiation losses to the environment.

$(\tau \alpha) \cdot I_{T}=\eta_{p v} \cdot I_{T}+U_{L, f} \cdot\left(T_{p v, f}-T_{a}\right)+U_{L, b} \cdot\left(T_{p v, b}-T_{a}\right)$

$U_{L, f}$ and $U_{L, b}$ stand for the thermal losses coefficient for the front and back side respectively, and are given by:

$U_{L, f}=h_{a, g-a}+h_{r, g-a}$

$U_{L, b}=h_{c, b-a}+h_{r, b-a}$

$h_{r, g-a}$ and $h_{r, b-a}$ stand for the thermal radiation coefficients for the front and back PV surface, respectively. $h_{c, g-a}$ and $h_{c, b-a}$ stand for the convection heat transfer coefficient for the front and back surface of the PV module, respectively, which differ to each other as analysed in the following.

\subsection{Natural convection from a PV module}

The natural heat convection coefficient from PV glass to air $h_{c, g-a}$ and PV back surface to air $h_{c, b-a}$ may be determined from the $N u$ number for the hot PV surface facing upward $N u_{f}$ and the hot PV surface facing downward $N u_{b}$ respectively, through the expression of the general form: $N u=h \cdot L / k_{a}$. L is the length of the module along the natural air flow direction. The Rayleigh number, $R a$, is calculated by the formula (Incropera and DeWitt, 1996):

$R a=\frac{g \cdot\left(1 / T_{f}\right) \cdot\left(T_{p v}-T_{a}\right) \cdot L^{\Omega}}{v \cdot \alpha}$

where:

$V$, is the air kinematic viscosity estimated at the boundary layer.

$T_{f}(\mathrm{~K})$, is the film temperature or temperature of the boundary layer, which according to Fujii and Imura (1972) may be approximated by: $T_{f}=T_{a}+0.25 \cdot\left(T_{p v}-T_{a}\right)$. All physical properties in the expressions to follow are evaluated at temperature $T=T_{p v}-0.25 \cdot\left(T_{p v}-T_{a}\right)$, (Fujii and Imura, 1972).

$\alpha$, is the thermal diffusivity of the air at temperature $T_{f}$.

\section{Front PV surface}

For the inclined front PV surface the $\mathrm{Nu}$ number may be determined through the following expressions proposed by Fujii and Imura (1972) for an inclined hot plate facing upwards. According to their study with a $30 \mathrm{~cm}$ heated plate facing upwards, their experimental data for various angles of plate inclination and with $R a>5 \cdot 10^{8}$ agreed well with eq.(7). Note that in the present study PV inclination $\beta$ is the angle of the PV plane with the horizontal, whereas in (Fujii and Imura, 1972) the angle $\theta$ is expressed with respect to the vertical. Thus, $\beta=90-\theta$. $\theta$ is kept in the following expressions to avoid confusion.

$N u_{f}= \begin{cases}0.13 \cdot\left\{(G r P r)^{1 / 3}-\left(G r_{c} P r\right)^{1 / 3}\right\}+0.56 \cdot\left(G r_{C} \operatorname{Pr} \cdot \cos \theta\right)^{1 / 4}, & \theta<60^{\circ} \\ 0.13 \cdot R a^{1 / 3}, & \theta \geq 60^{\circ}\end{cases}$

where $\operatorname{Pr}$ stands for the Prandtl number. $G r_{c}$ is the critical Grashof number corresponding to the transition region from laminar to turbulent flow, and according to the experimental data of Fujii and 
Imura (1972) takes values $5 \cdot 10^{9}, 2 \cdot 10^{9}, 10^{8}, 10^{6}$, for $\theta$ equal to $15^{\circ}, 30^{\circ}, 60^{\circ}, 70^{\circ}$ respectively. In order to estimate $\mathrm{Gr}_{\mathrm{c}}$ at any intermediate angle in the present study, an exponential fitting was applied to the aforementioned values which resulted in: $G r_{c}=1.327 \cdot 10^{10} \cdot \exp \left(-3.708 \cdot \theta_{r}\right)$, with $\theta_{\mathrm{r}}$ the angle in radians.

Eq. (7) is valid for $R a>5 \cdot 10^{8}$, which holds for all data in the present study. In case of smaller $R a$ values a similar set of equations is provided by Fujii and Imura (1972).

\section{Back PV surface}

For the inclined back PV surface at angle $\beta \geq 30^{\circ}\left(\theta \leq 60^{\circ}\right)$, the Nu number for a hot plate facing downwards may be determined through eq. (8) as recommended by Churchill and Chu (1975) and valid for the entire range of Ra.

$N u_{b}=\left[0.825+\frac{0.387 \cdot(R a \cdot \cos \theta)^{1 / 6}}{\left[1+\left(0.492 / \mathrm{Pr}^{1 / 6 / 16}\right]^{8 / 27}\right.}\right]^{2}, \quad 0^{\circ} \leq \theta \leq 60^{\circ}$

For the back PV surface inclined at angles $\beta<30^{\circ}\left(\theta>60^{\circ}\right)$ eq.(9) proposed by Fujii and Imura (1972) are used in the current algorithm. The first expression in eq.(9) for inclined surfaces $\left(\theta<88^{\circ}\right)$, is valid for $10^{5}<R a \cdot \cos \theta<10^{11}$, and the second one for the horizontal plate $\left(88^{\circ} \leq \theta \leq 90^{\circ}\right)$ is valid for $10^{6}<R a<10^{11}$. Although the first expression in eq.(9) is valid for all inclination angles $\beta$ above $2^{\circ}$, it is used up to $30^{\circ}$ from horizontal, while beyond that inclination eq.(8) is used as it is found in this study to provide a better correlation with the experimental data.

$N u_{b}=\left\{\begin{array}{lr}0.56 \cdot(R a \cdot \cos \theta)^{1 / 4}, & \theta<88^{\circ} \\ 0.58 \cdot(R a)^{1 / 5}, & 88^{\circ} \leq \theta \leq 90^{\circ}\end{array}\right.$

\subsection{Air forced flow heat convection from a PV module}

A wide range of formulae for the determination of the forced flow heat convection coefficient are available in the literature, as initially developed for solar collector thermal analysis (McAdams, 1954; Watmuff et al., 1977; Lunde, 1980; Sharples and Charlesworth, 1998; Cole and Sturrock, 1977; Sparrow et al., 1979; Sartori, 2006; Kendoush, 2009; Palyvos, 2008) and proposed equivalently for the thermal analysis of photovoltaics (Armstrong and Hurley, 2010; Mattei et al., 2006; Palyvos, 2008); some of these are also presented in Table 1 . The $h$ values for the forced convection are generally higher particularly at high wind velocities than the ones obtained by the aforementioned $\mathrm{Nu}$ relationships for natural flow. In Table 1, some of the expressions of $h$ are more specific considering separately the windward and leeward side of the module. Sharples and Charlesworth (1998) derived empirical linear (eqs.(13a)-(13e)) and power regressions of $h$ for different wind direction groups from experiments performed on a roof-mounted flat plate solar collector. Sartori (2006) proposed the set of eqs. (16a),(16b),(16c) providing $h$ according to the determined flow, whether laminar, fully turbulent or mixed, which includes the decay of the heat transfer along the length of the surface in the wind direction. Furthermore, eq.(17), proposed by Kendoush (2009), provides $h$ according to the angle of incidence of fluids flowing across a flat plate. 
Table 1. A sample of the available formulae for the determination of the air forced heat convection coefficient.

\begin{tabular}{|c|c|c|c|}
\hline & Air forced heat convection coefficient equation & Eq. \# & Authors \\
\hline 1. & $\begin{array}{l}h=3.8 \cdot v_{w}+5.7 \text { in this equation the effects of } \\
\text { free convection and radiation may be included } \\
\text { (Duffie and Beckman, 1980) }\end{array}$ & (10) & McAdams (1954) \\
\hline 2. & $h=3.0 \cdot v_{w}+2.8$ & (11) & Watmuff et al. (1977) \\
\hline 3. & $h=2.9 \cdot v_{w}+4.5$ & (12) & Lunde (1980) \\
\hline 4. & 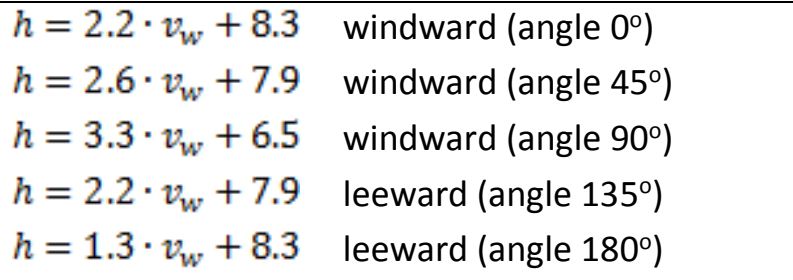 & $\begin{array}{l}(13 a) \\
(13 b) \\
(13 c) \\
(13 d) \\
(13 e)\end{array}$ & $\begin{array}{l}\text { Sharples and } \\
\text { Charlesworth (1998) }\end{array}$ \\
\hline 5. & 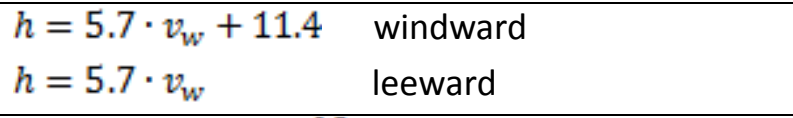 & $\begin{array}{l}(14 a) \\
(14 b)\end{array}$ & $\begin{array}{l}\text { Cole and Sturrock } \\
\text { (1977) }\end{array}$ \\
\hline 6. & $\begin{array}{l}h=4.96 \cdot v_{w}^{0.5} \cdot L_{c h}^{-0.5} \text { where } L_{c h}=4 \cdot A / S \\
\text { with A the plate area and } \mathrm{S} \text { its perimeter }\end{array}$ & (15) & Sparrow et al. (1979) \\
\hline 7. & $\begin{array}{l}h=3.83 \cdot v_{w}^{0.5} \cdot L^{-0.5} \text { laminar flow } \\
h=5.74 \cdot v_{w}^{0.8} \cdot L^{-0.2} \text { fully turbulent flow } \\
h=5.74 \cdot v_{w}^{0.8} \cdot L^{-0.2}-16.46 \cdot L^{-1} \text { mixed flows } \\
\text { where } L \text { is the surface length in the wind direction }\end{array}$ & $\begin{array}{l}(16 a) \\
(16 b) \\
(16 c)\end{array}$ & Sartori (2006) \\
\hline 8. & $\begin{array}{l}h=0.848 \cdot k \cdot\left(\cos \left(\alpha_{w}\right) \cdot v_{w} \cdot \operatorname{Pr} / v\right)^{0.5} \cdot d^{-0.5} \\
\text { where } d \text { is half the length of the surface }\end{array}$ & (17) & Kendoush (2009) \\
\hline
\end{tabular}

For the determination of the air forced flow heat convection coefficient the simulation model developed takes into consideration the wind velocity, the wind direction, the PV module orientation and inclination, and determines the windward and leeward side of the PV module whether front or back. For the determination of the air forced heat convection coefficient $h$ the applicability of the various models presented in Table 1 has been explored in this study and concluded in the use of the set of eqs.(16a),(16b),(16c), hereafter referred to as Sartori expressions, or eq.(17), hereafter referred to as Kendoush expression, for the windward side of the PV module. Both models consider the direction of the wind flow, indirectly in Sartori expressions through the length of the surface towards the wind direction, and directly in Kendoush expression through the angle of incidence of the wind on the surface.

In the current experimental study a double-axis sun-tracking PV system is used. For the determination of the length $L$ of the PV surface towards the wind direction, required in Sartori expressions, an angle $\gamma$ formed by the vectors of PV orientation $\left(\gamma_{\mathrm{pv}}\right)$ and wind direction $\left(\gamma_{\mathrm{w}}\right)$ is determined for the windward side of the module. Both $\gamma_{p v}$ and $\gamma_{w}$ are recorded with reference to the North. Angle $\gamma$ given by $\left|\gamma_{p v}-\gamma_{w}\right|$ is translated with respect to a reference line, which is the horizontal projection of the normal to the PV plane at the windward side. For an angle $\gamma<=45^{\circ}$, the length $L$ in the wind direction is considered equal to the height of the PV module, while for an angle $\gamma>45^{\circ}, L$ is considered equal to the width of the PV module. For the few cases where the front PV side is windward and wind flows in parallel to the PV array, from the other edge of the PV array towards the module under study, then $L$ is considered equal to the length of the array. 
For the determination of the angle of incidence $\alpha_{w}$ of the wind stream on the PV module surface required in Kendoush expression, the PV inclination, orientation and wind direction are considered. The angle between the incident wind stream and the normal to the PV module surface is determined by eq.(18) derived from spherical trigonometry, see Fig.1. Eq.(18) is used both for the front and the back PV side when windward.

$\cos \left(a_{w}\right)=\cos (90-\beta) \cdot \cos (\gamma)$

where $\gamma$ is determined, as earlier stated, with reference to the windward side of the module, by: $\gamma=\left|\gamma_{p v}-\gamma_{w}\right|$.
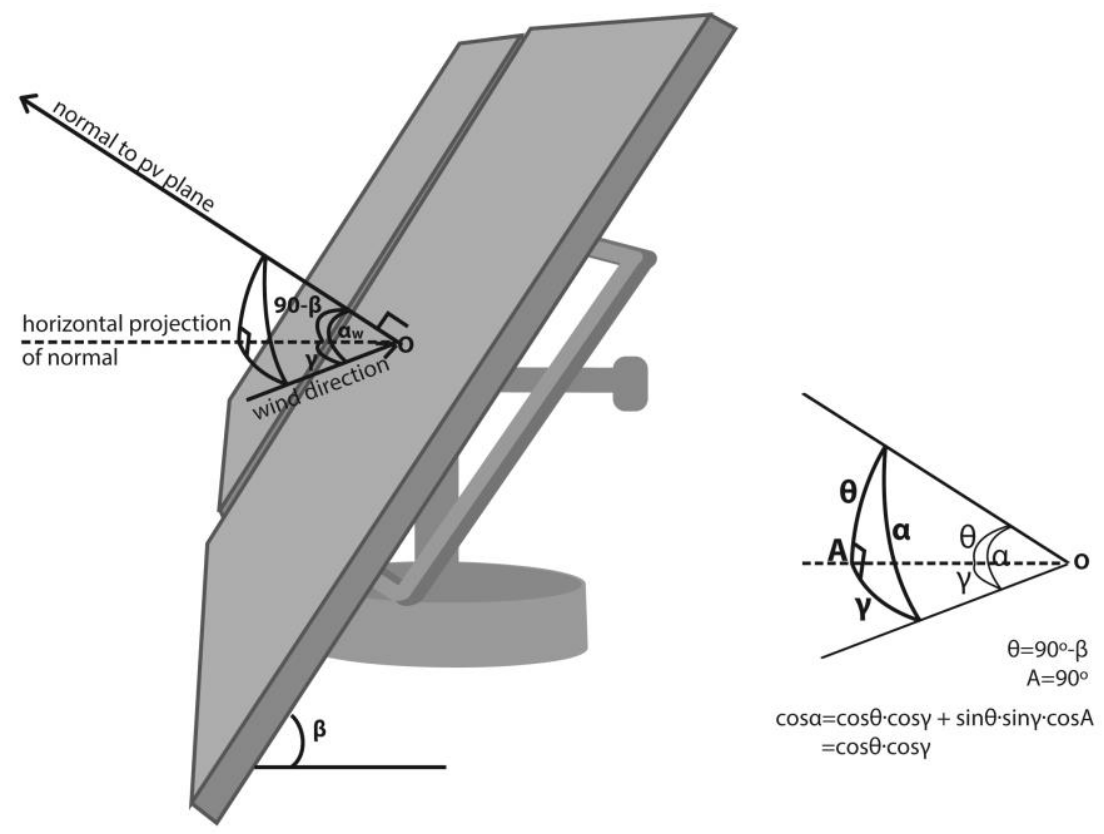

Fig. 1. Tracker geometry and wind incidence angle

For the determination of $h$ using Sartori expressions the ratio $x_{C} / L$ is required to evaluate the type of flow. The critical length $x_{c}$ is given by $x_{c}=R e_{x_{i} c} \cdot v / v_{w}$ (Incropera and DeWitt, 1996), and the critical Reynolds number $R e_{x, c}$ is considered equal to $4 \mathrm{E} 05$ (Sartori, 2006). Thus, according to Sartori (2006), if the ratio $x_{c} / L \geq 0.95$ laminar flow is considered and eq.(16a) is employed, while for $x_{c} / L<0.95$ mixed flow is considered with transition from laminar to turbulent flow described by eq.(16c). The case of $x_{c}<<L$ indicates fully turbulent flow, with eq.(16b). For analogy, with the ratio $x_{c} / L$ in the fully turbulent flow, a threshold value of 0.05 was set. Thus, according to the ratio $x_{c} / L$ evaluated, one of the three eqs.(16a),(16b),(16c) is used for the forced convection coefficient at the windward side of the module. In certain wind directions the actual path of the wind encounters obstacles due to the frame/base and mechanism of the tracker. These are cases where the back PV side is windward and the wind flows along the width of the module $\left(\gamma>45^{\circ}\right)$ and encounters the obstacles of the frame/base before reaching the module under study. For these cases only, if the wind velocity was greater than $3 \mathrm{~m} / \mathrm{s}$ the flow was considered turbulent and eq.(16b) was employed irrespective of the value of the ratio $x_{c} / L$. This was based on (Sartori, 2006) that recommends using eq.(16b) for fully turbulent flow if there is an obstacle close to the leading edge of a solar panel. 
For the leeward side of the module, as wind direction information is irrelevant, Sartori expressions are used in the simulation model, however with the length $L$ now given by $L=4 \cdot A / S$, where $A$ the module area and $S$ its perimeter, as in (Sparrow et al., 1979). This approach for the leeward side was found to provide good agreement with the experimental data, as will be shown in Section 4 .

The simulation model was also implemented with $h$ determined for the windward side of the PV module using Kendoush expression. In this approach, $\alpha_{w}$ for the windward side is determined as mentioned earlier through eq.(18). For the leeward side of the module, Sartori expressions with $L$ as defined above are also used here. Kendoush and Sartori expressions are governed by a similar power law and their combination for the windward and leeward side of the module, provides also a good agreement with the experimental data, as will be shown in Section 4.

\subsection{Combined Natural and Forced Convection}

For the determination of the overall value of $h$, the ratio $G r_{L} / R e_{L}{ }^{2}$ is estimated (White, 1988), so that when $G r_{L}<<R e_{L}{ }^{2}$ the natural convection is neglected, when $G r_{L}>>R e_{L}{ }^{2}$ the forced convection is neglected. Combined natural and forced convection is considered when $0.01<G r_{L} / R e_{L}{ }^{2}<100$ (White, 1988).

The overall value of $h$ taking into account the combined natural and forced flow is estimated using the expression (Churchill, 1977):

$N u_{\text {overall }}^{m}=N u_{\text {natural }}^{m} \pm N u_{\text {forced }}^{m}$

Churchill (1977) recommends using $m=3$ for assisting or opposing flow with the positive or negative sign respectively for vertical and inclined plates.

Thus, the overall $h_{c, g-a}$ and $h_{c, b-a}$ for the front and the back PV surface may be given by:

$$
\begin{aligned}
& h_{c, g-a}^{m}=h_{a, g-a(\text { natural })}^{m}+h_{a, g-a(\text { forced })}^{m} \\
& h_{c, b-a}^{m}=h_{c, b-a(\text { natural })}^{m} \pm h_{c, b-a(\text { forced })}^{m}
\end{aligned}
$$

The assisting or opposing mode of the forced flow heat convection with respect to natural flow is taken into account. For the PV front side, the forced flow heat convection is assisting to the natural flow. For the PV back side, assisting mode is considered if this side is leeward, whereby the positive sign is used in eq.(20b), and opposing mode if this side is windward, whereby the negative sign is used. A value of $m$ equal to 3 is used, as it is valid for inclined surfaces and the smallest inclination angle in this study is $15^{\circ}$. For horizontal PV surfaces a value of $m=7 / 2$ may be used instead (Incropera and DeWitt, 1996).

\subsection{Thermal radiation emission from the PV front and back side}

The linear thermal radiation coefficients $h_{r, g-a}$ and $h_{r, b-a}$ for the front and back side of the PV module are calculated, respectively, by:

$$
\begin{aligned}
h_{r, g-a}= & \varepsilon_{g} \cdot F_{p v, f-s k y} \cdot \sigma \cdot\left(T_{p v, f}^{2}+T_{s}^{2}\right) \cdot\left(T_{p v, f}+T_{s}\right) \\
& +\varepsilon_{g} \cdot F_{p v, f-g r o u n d} \cdot \sigma \cdot\left(T_{p v, f}^{2}+T_{g r}^{2}\right) \cdot\left(T_{p v, f}+T_{g r}\right)
\end{aligned}
$$




$$
\begin{aligned}
h_{r, b-a}= & \varepsilon_{b} \cdot F_{p v, b-s k y} \cdot \sigma \cdot\left(T_{p w, b}^{2}+T_{s}^{2}\right) \cdot\left(T_{p v, b}+T_{s}\right) \\
& +\varepsilon_{b} \cdot F_{p v, b-g r o u n d} \cdot \sigma \cdot\left(T_{p v, b}^{2}+T_{g r}^{2}\right) \cdot\left(T_{p v, b}+T_{g r}\right)
\end{aligned}
$$

where, $\varepsilon_{g}$ is the emissivity coefficient of the glass cover and $\varepsilon_{b}$ the emissivity coefficient of the module back side determined equal to 0.85 and 0.91 respectively. $\sigma$ is the Stefan-Boltzmann constant equal to $5.6710^{-8} \mathrm{~W} / \mathrm{m}^{2} \mathrm{~K}$. $T_{g r}$ is the ground temperature, and $T_{s}$ is the sky temperature given by eq.(23).

$T_{s}=0.0552 \cdot T_{a}^{1.5}$

$F_{p v, f-s k y,} F_{p v, f-g r o u n d}$ stand for the view factors between the PV front surface and the sky or the ground, respectively. Similarly, the view factors $F_{p v, b-s k y}, F_{p v, b-g r o u n d}$ correspond to the PV back surface and the sky or ground, respectively. Formulae for the above view factors are given below:

$$
\begin{aligned}
& F_{p v_{1} f-s k y}=(1+\cos (\beta)) / 2 \\
& F_{p v_{1} f-\text { ground }}=(1-\cos (\beta)) / 2 \\
& F_{p v_{s}, b-s k y}=(1+\cos (\pi-\beta)) / 2 \\
& F_{p v_{b}, b-\text { ground }}=(1-\cos (\pi-\beta)) / 2
\end{aligned}
$$

\subsection{Determination of the $f$ coefficient}

$T_{p v}$ at the front and back PV side differs, especially as the overall heat transfer coefficients $U_{L, f}$ and $U_{L, b}$ according to the previous analysis depend on the PV module inclination, the wind velocity and the relative wind direction with respect to the PV module orientation. In general, based on heat transfer analysis, $T_{p v}$ also depends on the PV cell structural components, the intensity of the solar radiation on the module, and the ambient temperature. In fact, a PV module under operation exhibits a temperature distribution, whereby small to large differences in the temperature of the cells of the module may be apparent (Kaplani and Kaplanis, 2012; Kaplani, 2012). Thus, $T_{p v}$ refers to the average temperature of the module. Furthermore, it has been shown that the PV cell temperature is higher than the Tedlar or the glass temperature by about $1-3{ }^{\circ} \mathrm{C}$ (King et al., 2004; Tina, 2010). Moreover, in (Tina, 2010) the glass temperature was experimentally measured and theoretically calculated lower than the Tedlar temperature.

In the simulation model developed the difference between $T_{p v, f}$ and $T_{p v, b}$ was neglected. This simplification was done for comparison reasons of the $f$ coefficient determined theoretically and experimentally as will be described in the following, and since PV temperature was measured at the back side of the PV module. Assuming $T_{p v, f}=T_{p v, b}$ in eq.(3) the following simplified expression is obtained giving an approximation of the temperature at the back surface of the PV module. Note that a sensitivity analysis was performed on the effect of this assumption and is presented in the Discussion section.

$T_{p v}=T_{a}+\frac{\left((\tau \alpha)-\eta_{p v}\right) \cdot I_{T}}{U_{L, f}+U_{L b}}$

Eq.(25) may be written in the following general form: 
The $f$ coefficient relates $T_{p v}$ with $T_{a}$ and $I_{T}$, and has been addressed by previous investigators as in (King et al., 2004; Faiman, 2008; Skoplaki et al., 2008; Kaplanis et al., 2008). King et al. (2004) have given $f$ as an exponential function of wind speed. Faiman (2008) has shown $1 / f$ to be linearly related to wind speed. Skoplaki et al. (2008) have presented $f$ as a function of wind speed in combination with a mounting coefficient normalised to the free standing PV array. Kaplanis et al. (2008) investigated $f$ for the natural convection and presented it as a quadratic cosine function of the PV inclination angle.

In the present study the $f$ coefficient is estimated in relation to the overall heat losses, incorporating wind velocity, wind direction, PV inclination and orientation information. From eq.(25), the $f$ coefficient is determined by:

$$
f=\frac{(\tau \alpha)-\eta_{p v}}{U_{L f f}+U_{L b}}
$$

The transmission-absorption coefficient ( $\tau \alpha$ ) is assumed equal to 0.81 (Mattei et al., 2006; Bardhi et al., 2012). The PV efficiency $\eta_{p v}$ in eq.(25) is the corrected efficiency due to temperature and the intensity of solar irradiance, and is estimated according to eq.(2). It should be noted that for an accurate evaluation of $f$ and assessment of the heat transfer equations used, the measured $T_{p v}$ was taken as input in the estimation of the boundary layer temperature $T_{f}$, also in the thermal radiation coefficients $h_{r, g-a}$ and $h_{r, b-a}$ and in the evaluation of $\eta_{P V}$ at operating conditions. Alternatively, an approximation of $T_{p v}$ could be used for this, as through the expression of King et al. (2004) $T_{c e l l}=T_{p v, b}+\Delta T \cdot I_{T} / 1000$ where $\Delta T$ is the temperature difference between the cell and the back $\mathrm{PV}$ surface at $1000 \mathrm{~W} / \mathrm{m}^{2}$ and typically is 2 to $3^{\circ} \mathrm{C}$ for free standing modules, or as in PV temperature prediction studies (Notton et al., 2005; Jones and Underwood, 2001; Amy de la Breteque, 2008; Tina, 2010) along with a precise estimation of $T_{p v}$ at front and back side. However, an explicit theoretical prediction of $T_{p v}$ is outside the scope and focus of this study.

$f$ is determined theoretically and experimentally generally for free standing PV module using data from a sun-tracking PV system and, thus, exploiting a wide range of possible PV inclination and orientation angles. The flowchart of the simulation algorithm developed for the determination of $f$ is given in Fig.2. In the flowchart for the windward case the Sartori expressions are displayed. In their position Kendoush expression may be used instead.

The $f$ coefficient generally depends on:

1. the solar radiation spectrum (indirectly). This effect was neglected here as it is outside the objective of the current study.

2. the inclination angle $\beta$, as $h_{c, g-a}$ and $h_{c, b-a}$ generally depend on this angle

3. both types of heat convection; natural and forced flow

4. the pattern of air flow along the PV panel; laminar or turbulent

5. the wind velocity and relative wind direction with respect to the PV module surface

6. the type of the PV installation; i.e. free standing PV, BIPV. In this study only PV system operating in free environment has been considered. 


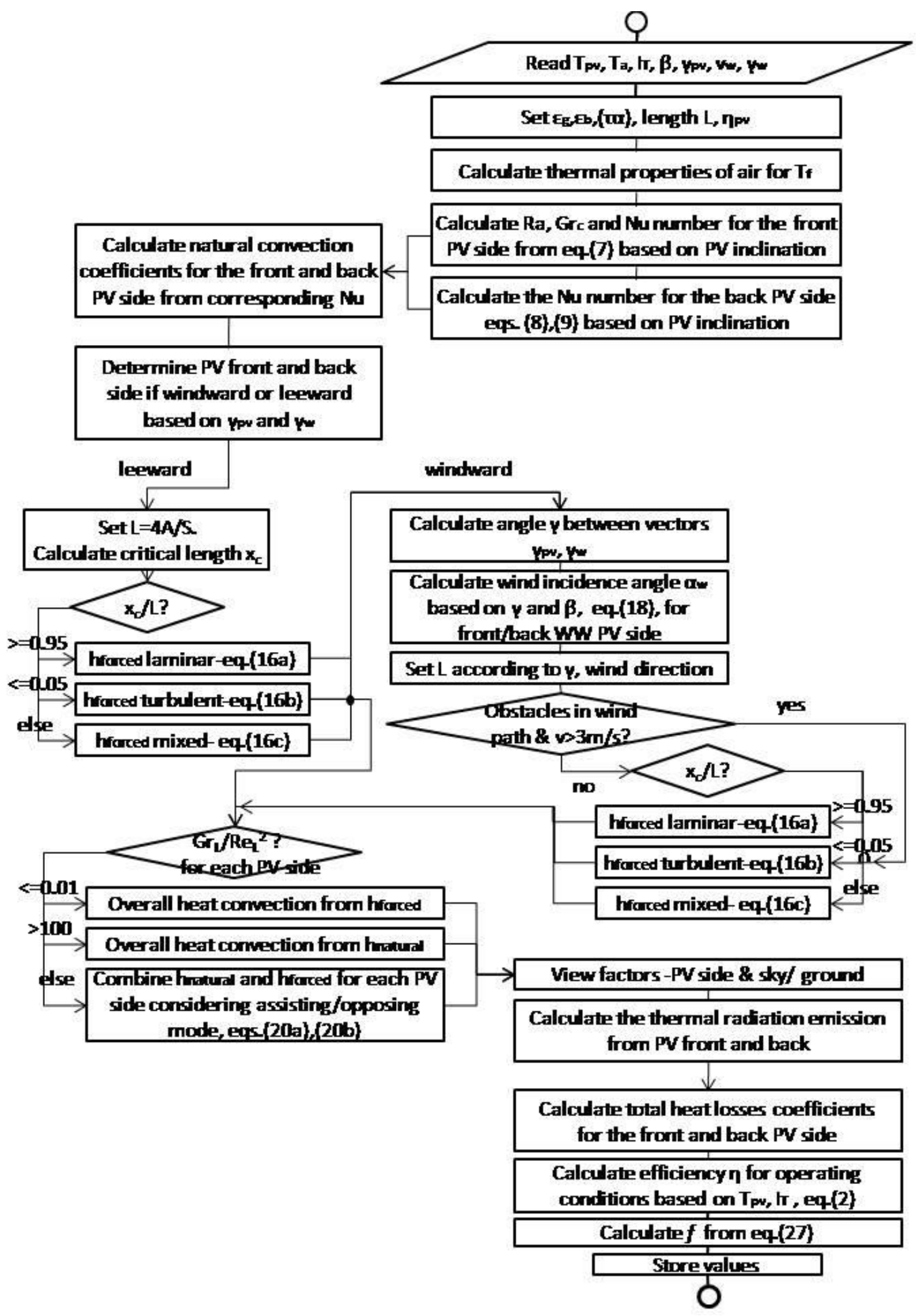

Fig.2. Flowchart of simulation algorithm. 


\section{Description of PV configuration and experimental procedure}

The experimental data analysed in this paper were obtained from monitoring a double-axis suntracking PV system and meteorological conditions at the terrace of the RES laboratory of TEI of Patras, presented in Fig.3a. The double-axis sun-tracking PV system consists of 4 poly-crystalline modules each of nominal power $120 \mathrm{Wp}$, nominal efficiency $12 \%$, and dimensions $1.490 \times 0.674 \times$ $0.0046 \mathrm{~m}$. The temperature coefficient for power is given by the manufacturer $-0.43 \% /{ }^{\circ} \mathrm{C}$. The data monitored for a period of one year, include the module temperature $T_{p v}$, via a Cu-Const thermocouple placed at the back of the PV module, and the global solar radiation IT on the PV plane, via means of a Kipp \& Zonen CM11 pyranometer fixed on the plane of the PV modules. The data were recorded for a period of 4 minutes at the beginning of every hour of the day via means of a datalogger with a sampling rate of $500 \mathrm{~ms}$. The wind velocity and wind direction measured at a height of $6 \mathrm{~m}$ from the ground of the terrace via means of a R.M. Young 05103 wind sensor, and the ambient temperature via means of a MP101A sensor, were monitored at one minute intervals throughout the year, and recorded 1 minute averages via means of a separate datalogger with sampling rate of $10 \mathrm{~s}$. The two dataloggers are synchronised and corresponding 4 minute averages from the tracker and the meteo station data were easily calculated. The instantaneous wind velocity $v_{w, \text { ref }}$ recorded at the relative height of $6 \mathrm{~m}$ was converted to a relative height of $1 \mathrm{~m}$ above the suntracking PV system using the following power law expression. Since 1 min average wind speed values are recorded at the reference height, for higher accuracy a variable exponent $n$ is used according to eq.(28b) proposed by Justus and Mikhail (1976).

$\frac{v_{w}}{w_{w r e f}}=\left(\frac{\mathrm{z}}{z_{\text {ref }}}\right)^{n}$

$n=\frac{0.37-0.0881 \cdot \ln \left(v_{\text {wer ref } f}\right)}{1-0.0881 \cdot \ln \left(z_{\text {ref }} / 10\right)}$

where, $z_{\text {ref }}$ is the reference height measured from ground, and $z$ the new height.

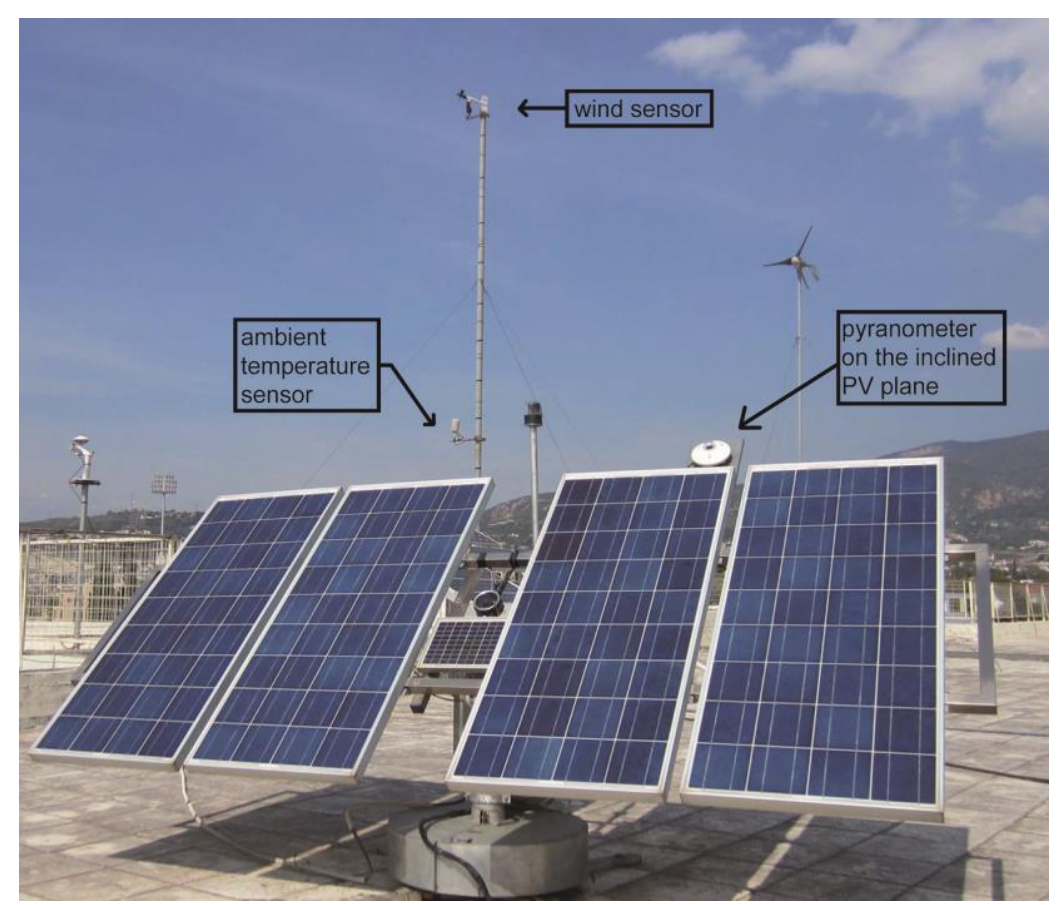

(a) 


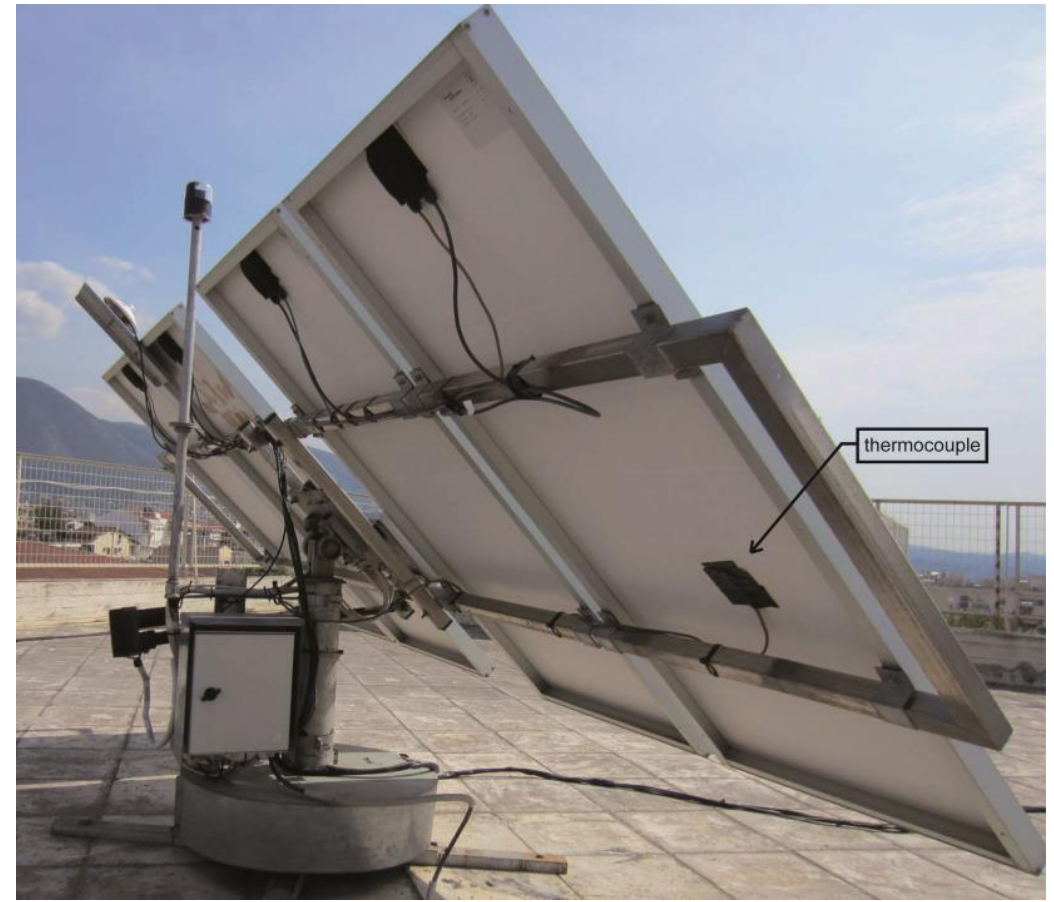

(b)

Fig. 3. Double-axis sun-tracking PV system and meteorological station used in the current experimental study, (a) front, (b) back PV side.

The measured data were then screened to only clear sky days, for a more reliable analysis of the $f$ coefficient relating $I_{T}$ and $T_{\alpha}$ to $T_{P V}$, see eq.(26). It is assumed that the temperature measured by the thermocouple positioned at the back of the module (see Fig.3b), represents its average temperature. A quality check led to the removal of $1 \%$ of the data which displayed extreme $f$ values, all of which corresponded to either early morning (first hour after sunrise) or late evening measurements (last hour before sunset) when thermal transients are significant. A statistical analysis of meteorological data was performed to examine the degree of the fluctuations within the averaging 4 minute period. The standard deviations of the solar radiation incident on the PV plane at the recording periods have a median of $1.73 \mathrm{~W} / \mathrm{m}^{2}$, and the ambient temperature $0.08^{\circ} \mathrm{C}$. The standard deviations of the wind velocity have a median of $0.37 \mathrm{~m} / \mathrm{s}$ and wind direction 12.9 degrees.

Placed in a free environment at the terrace, the sun-tracking PV system was able to take various inclination angles $\beta$ from $15^{\circ}-85^{\circ}$, and orientation angles $\gamma_{\mathrm{PV}}$ from $75^{\circ}$ to $285^{\circ}$ as recorded. Wind velocity $\mathrm{v}_{\mathrm{w}}$ as measured and translated to $1 \mathrm{~m}$ height above the tracker varied from 0 to $8.5 \mathrm{~m} / \mathrm{s}$, and wind direction $\gamma_{w}$ from $0^{\circ}-356^{\circ}$. The angle of incident of the wind stream on the PV module (either at the front or the back side) was estimated based on the direction of the wind $\gamma_{w}$ and the azimuth of the PV surface $\gamma_{P V}$ from eq.(18). The ambient temperature $T_{\alpha}$ varied in the region of $4^{\circ}-37^{\circ} \mathrm{C}$, and the global solar radiation on the PV plane $I_{T}$ in the region of $100-1100 \mathrm{~W} / \mathrm{m}^{2}$.

The emissivity of the front and back side of the PV module was estimated experimentally using an IR thermocamera type TROTEC ICO80LV and a type-K thermocouple, by varying the emissivity setting $\varepsilon$ in the IR thermocamera until the temperature indications from the two sensors coincided. The ambient temperature and the relative humidity based on the measurements of the MP101A sensor were also applied as settings in the IR camera. The emissivity estimated for the front and back side of the PV module was 0.85 and 0.91 respectively. 


\section{Analysis of Results}

From the experimental data of $T_{P V}, T_{\alpha}$ and $I_{T}$ recorded, the $f$ coefficient was determined based on eq.(26). These values were then compared to the values of $f$ obtained from the simulation algorithm described in Section 2, where $f$ is given by eq.(27). The heat losses coefficients $U_{L, f}$ and $U_{L, b}$ are calculated as earlier described taking into account each side of the PV module whether leeward or windward, the wind incidence angle on the PV module, and, all potential modes of heat transfer via natural convection, air forced convection, and radiated heat.

Fig. 4 presents values of $f$ obtained from the experimental data in relation to wind velocity, compared to the values of $f$ provided by the simulation algorithm using Sartori expressions for the air forced convection coefficient. The values of $f$ provided by the simulation algorithm are determined for the same conditions, PV inclination, orientation, wind velocity and direction as with the experimental data. The comparison of $f$ values experimentally determined and theoretically evaluated shows a good agreement, with Pearson's correlation coefficient $r=0.665$ significant at the 0.01 level and root-mean-square error (RMSE) equal to $0.004 \mathrm{~m}^{2} \mathrm{~K} / \mathrm{W}$.

The values of $f$ provided by the simulation algorithm when using Kendoush expression for the air forced convection coefficient for the windward (WW) and Sartori expressions with $L$ given by $4 \mathrm{~A} / \mathrm{S}$ for the leeward (LW) side of the module, are compared with the experimental data in Fig.5. The combination of Kendoush expression for the windward and Sartori for the leeward provides $f$ values in good agreement with the experimental data, with correlation coefficient $r=0.641$ significant at the 0.01 level and RMSE equal to $0.004 \mathrm{~m}^{2} \mathrm{~K} / \mathrm{W}$. Both approaches for the air forced convection provide a good agreement with the experimental data.

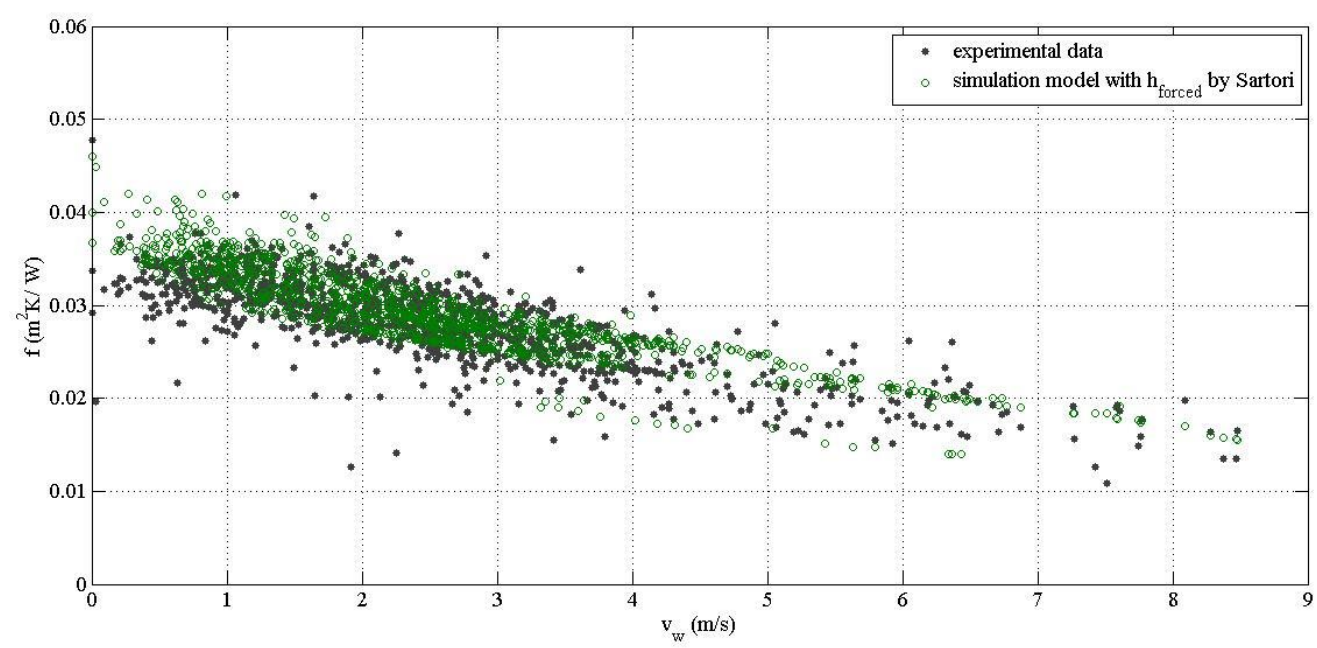

Fig. 4. Comparison of the $f$ coefficient determined experimentally and evaluated through the simulation model using the forced convection coefficient of Sartori -WW and Sartori with $L=4 \mathrm{~A} / \mathrm{S}$ for -LW. 


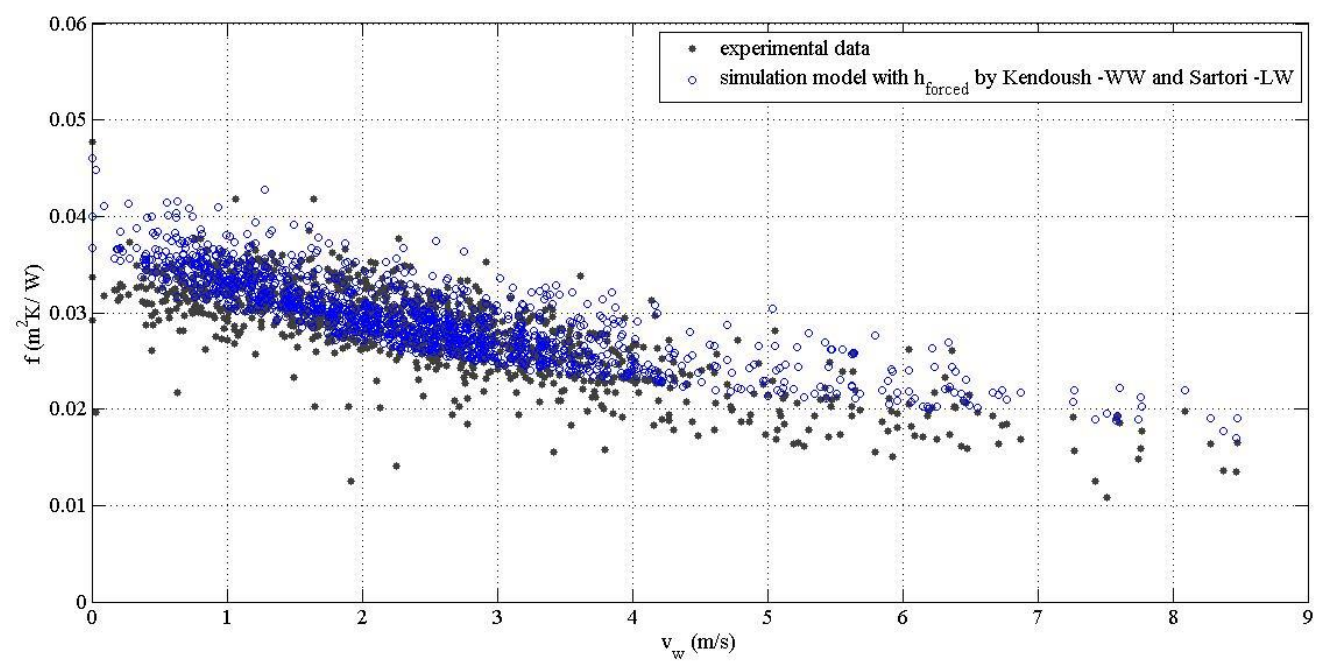

Fig. 5. Comparison of the $f$ coefficient determined experimentally and evaluated through the simulation model using the forced convection coefficient of Kendoush -WW and Sartori with $L=4 \mathrm{~A} / \mathrm{S}$ for -LW.

Fig. 6 provides the air forced convection coefficient $h$ obtained by the two approaches for the windward and the leeward side of the module (either front or back) in relation to wind velocity. $h$ is determined for the corresponding experimental conditions of the measurements, the PV inclination, orientation, wind velocity and direction. Kendoush expression generates scattered $h$ values which depend on the wind incidence angle on the PV surface. These values lie on or below the $h=0.848 \cdot k \cdot\left(v_{w} \cdot \operatorname{Pr} / v\right)^{0.5} \cdot d^{-0.5}$ curve for wind incidence angle normal to PV plane $\left(a_{w}=0^{\circ}\right)$. Eq.(17) results in 0 for wind incidence angle parallel to the PV plane $\left(a_{w}=90^{\circ}\right)$. The wind incidence angle evaluated from the experimental data of this study varied between $12^{\circ}$ to $90^{\circ}$. The $h$ values for the leeward side determined using Sartori expressions with $L=4 \mathrm{~A} / \mathrm{S}$ are also given in Fig.6. From a detailed analysis that was carried out it became clear that $h$ for the windward side determined using Kendoush expression is higher than the leeward $h$ for wind incidence angles up to about $60^{\circ}$, while for higher angles the leeward $h$ becomes greater than the windward $h$. Sparrow et al. (1982) have reported cases where $h$ for leeward is higher than the respective for the windward side. The resulting $h$ using Sartori expressions for the windward side gives evidence of laminar, mixed and turbulent flow. The ratio $x_{c} / L$ determined from the experimental data did not result in turbulent flow at any case. However, turbulent flow was considered, as mentioned in Section 2.2, in cases where the tracker frame/base formed obstacles in the wind path. For the leeward side, the flow turns from laminar to mixed at wind velocities around $8 \mathrm{~m} / \mathrm{s}$, whereas for the windward side and wind flowing across the module the flow becomes mixed for wind velocities above $5 \mathrm{~m} / \mathrm{s}$ (see Fig.6).

For comparison of the estimated $f$ with air forced convection determined through other expressions for the windward and leeward PV side, the simulation algorithm was also executed with the forced convection coefficient calculated from eqs.(13a)-(13e) proposed by Sharples and Charlesworth (1998), and, also, from eqs.(14a),(14b) proposed by Cole and Sturrock (1977). The results presented in Fig.7 show a large deviation from the experimental data, due to the empirical nature of these formulae. Furthermore, eq.(15) proposed by Sparrow et al. (1979) for the windward side was also combined with Sartori expressions with $L$ given by $4 A / S$ for the leeward side. The values of the $f$ coefficient provided by the simulation algorithm are displayed in Fig.7. This is a rather good approximation of $f$, however does not include the effect of the wind incidence angle on the PV surface. The air forced convection coefficient $h$ generated by the various expressions is displayed in Fig.8. 


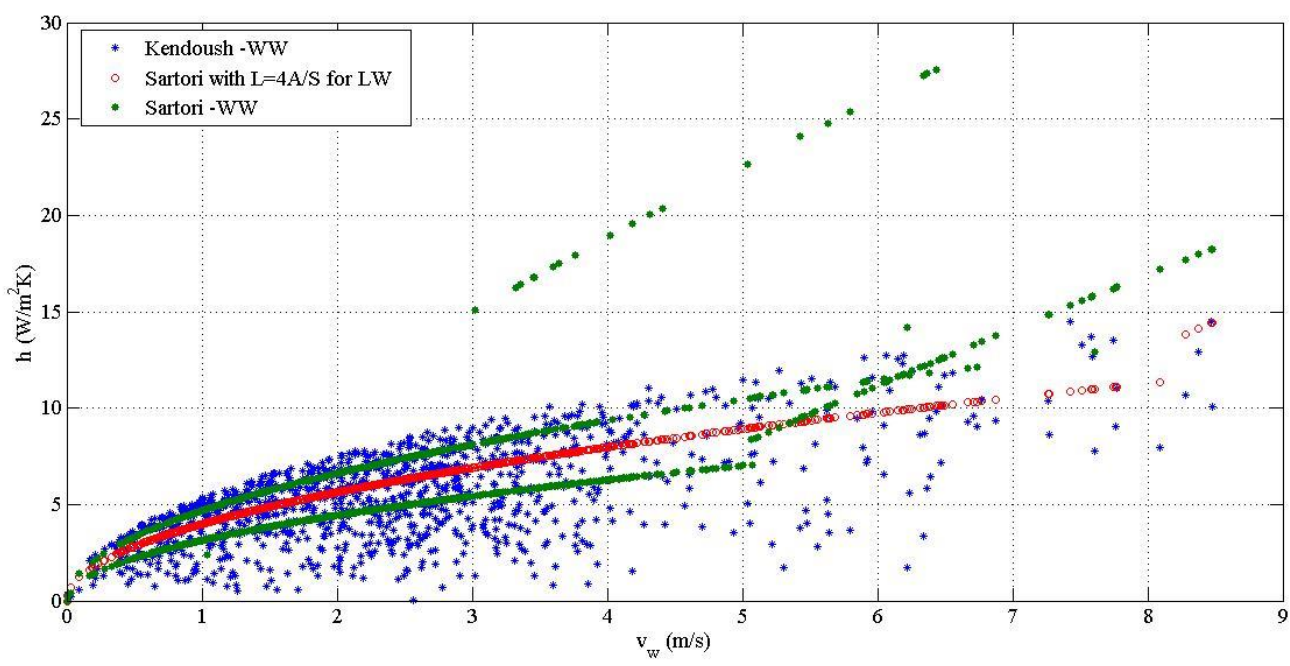

Fig. 6. Forced convection coefficient generated with Sartori -WW, Kendoush -WW and Sartori with $L=4 A / S$ for $-L W$ for the corresponding environmental conditions of the experimental data.

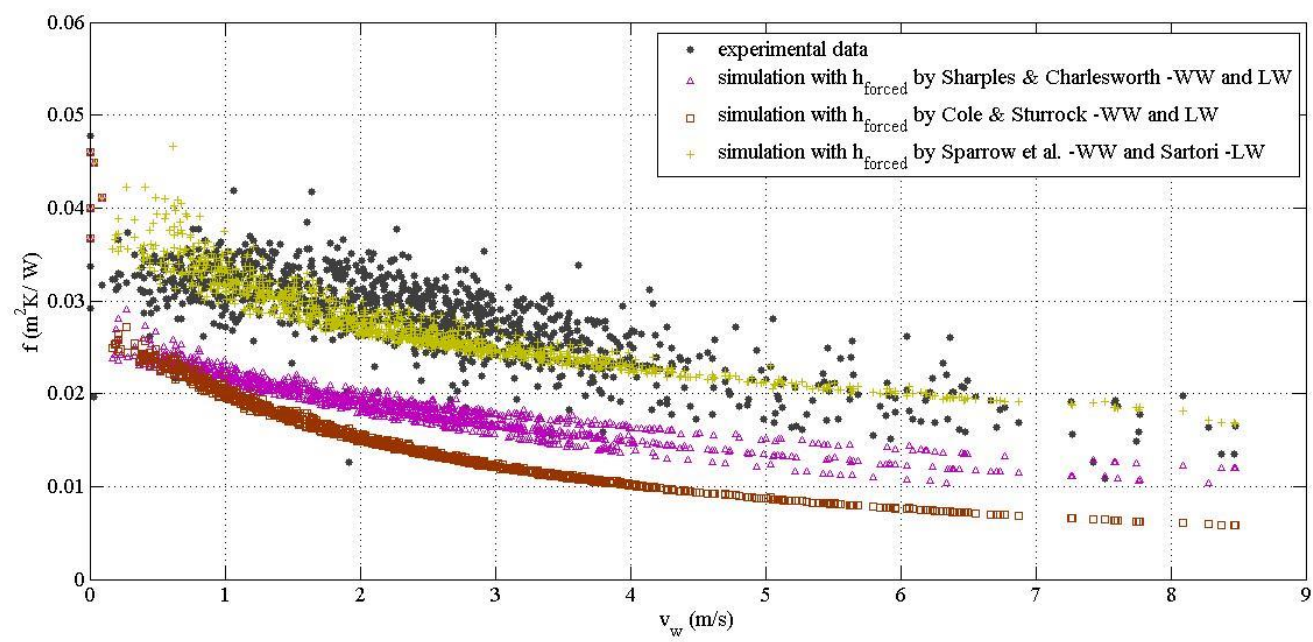

Flg.7. Comparison of the $f$ coefficient determined experimentally and evaluated through the simulation model using for forced convection the different expressions: Sharples \& Charlesworth WW -LW, Cole \& Sturrock -WW-LW, Sparrow et al. -WW -Sartori with $L=4 A / S$-LW.

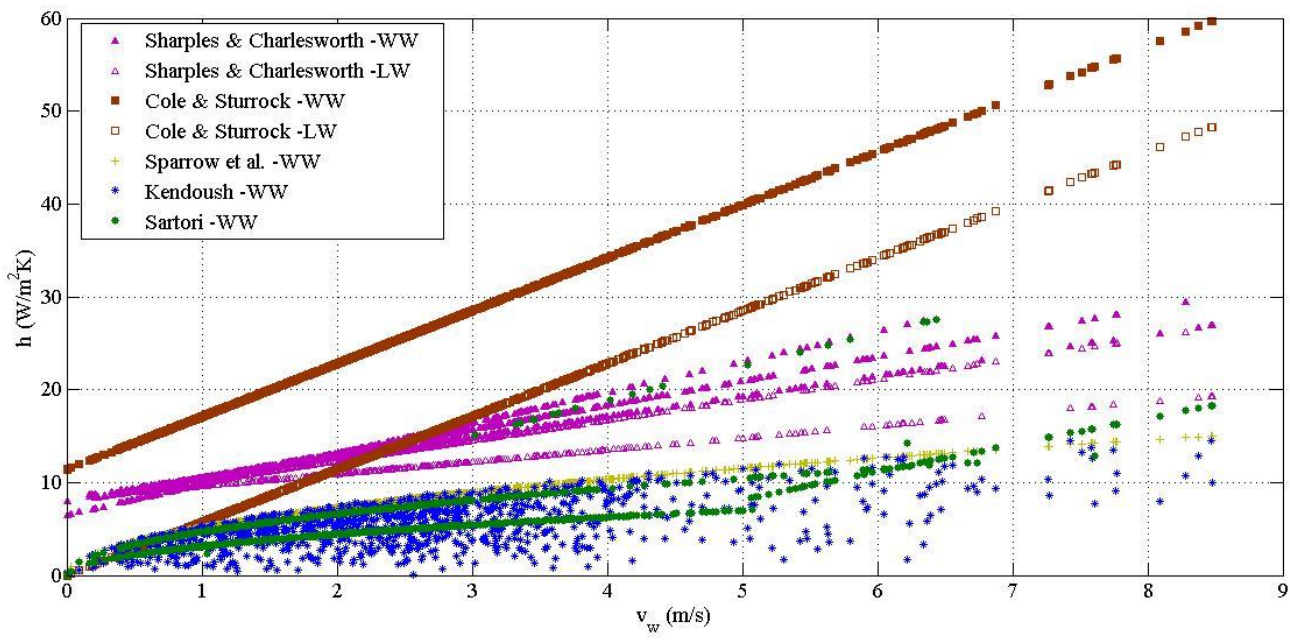

Fig.8. Forced convection coefficient estimated for the same experimental conditions with the various empirical and theoretical models. 
The effect of the wind incidence angle on the forced convection coefficient $h$ for the windward side estimated using Kendoush expression and Sartori expressions for the various experimental conditions is shown in Figs. 9a and 9b, respectively. Only $h$ for the windward side is strongly related to the wind incidence angle. The effect of $a_{w}$ on $h$ is given in Figs. 9a and 9b irrespective of the wind velocity. In Fig.9a it may be observed that Kendoush expression gives higher $h$ at low wind incidence angles. $h$ decreases with increasing $a_{w}$, reaching 0 at $90^{\circ}$ wind incidence angle. On the other hand, the $f$ coefficient provided by the simulation model being inversely related to the heat losses is affected in the opposite way, increasing as the wind incidence angle increases. This is also supported by the experimental data as will be shown. The trend line in Fig.9a presents a general trend of the increase of determined $f$ with increasing wind incidence angle. A detailed analysis will follow to examine any effects of wind velocity on the way $f$ relates to $a_{w}$. Fig.9b presents the effect of the wind incidence angle on the forced convection coefficient estimated using Sartori expressions for the windward side. An opposite trend compared to $h$ by Kendoush is exhibited here. Mainly due to the length of the module in the wind direction, Sartori expressions result in higher heat convection when the wind flows in parallel to the PV module and has lower effect at small wind incidence angles.

Information on the PV inclination angle $(\beta)$ is incorporated within the wind incidence angle through eq.(18). However, it is also of interest to examine $h$ and $f$ with respect to angle $\beta$. Figs. 10a and 10b show respectively the forced convection coefficient $h$ determined using Kendoush expression and Sartori expressions, respectively, for the windward side, and the various PV inclination angles irrespective of wind velocity and wind incidence angle. The $f$ coefficient provided by the simulation model is also displayed along with a trend line that reflects an increase of $f$ with increasing $\beta$, that is present in both approaches. However, as will be analysed in the following this effect is not maintained in the entire wind velocity range.

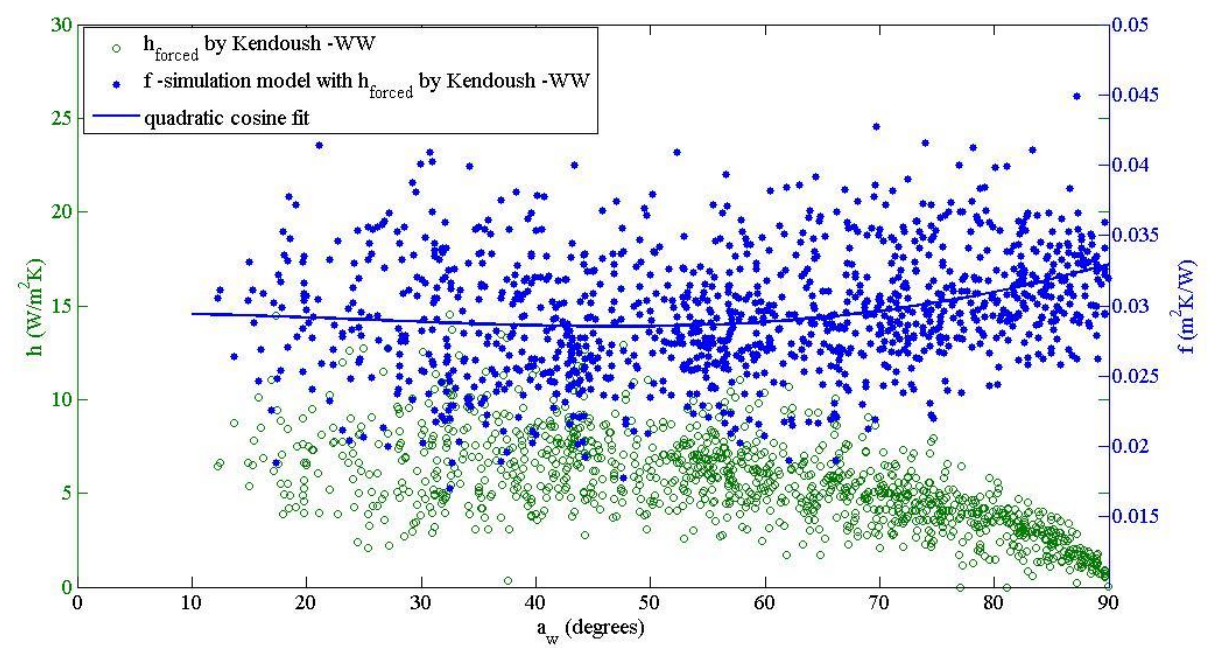

(a) 


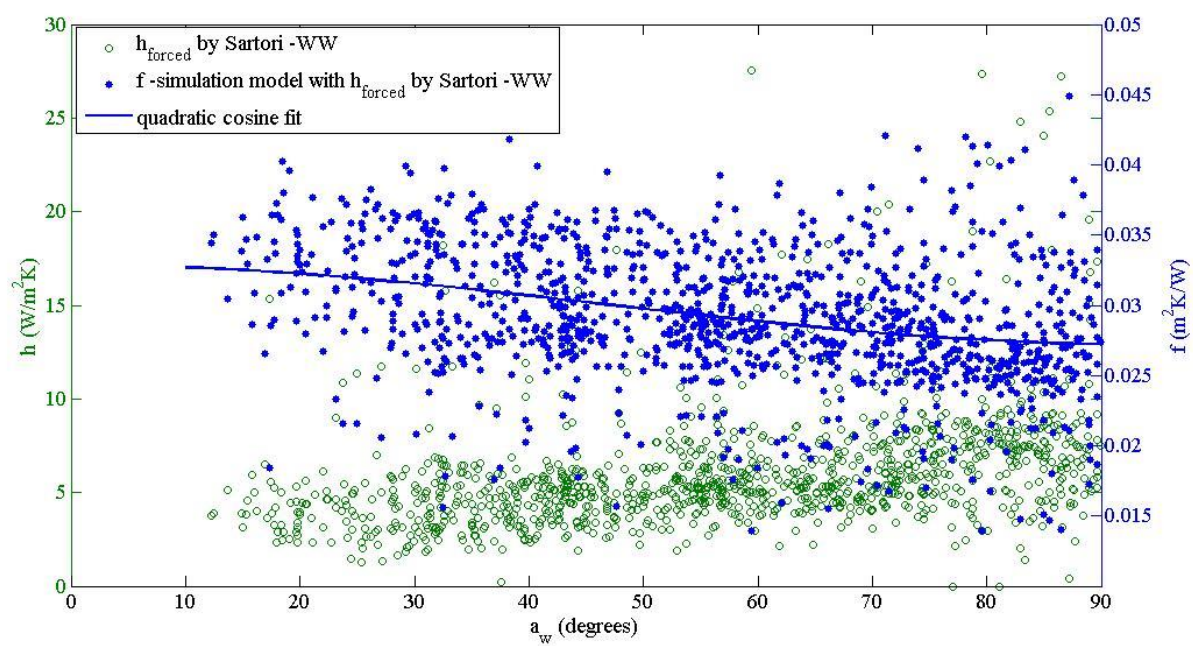

(b)

Fig.9. Forced convection coefficient and the $f$ coefficient provided by the simulation model in relation to the wind incidence angle on the PV module, using (a) Kendoush -WW and (b) Sartori -WW expressions.

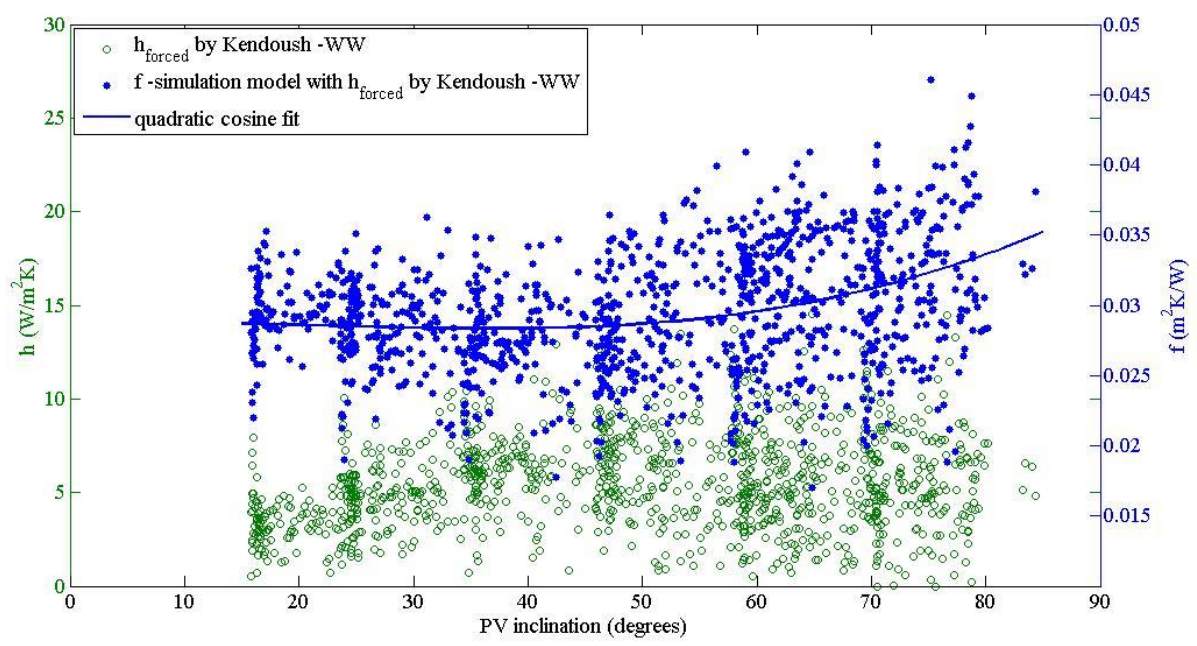

(a)

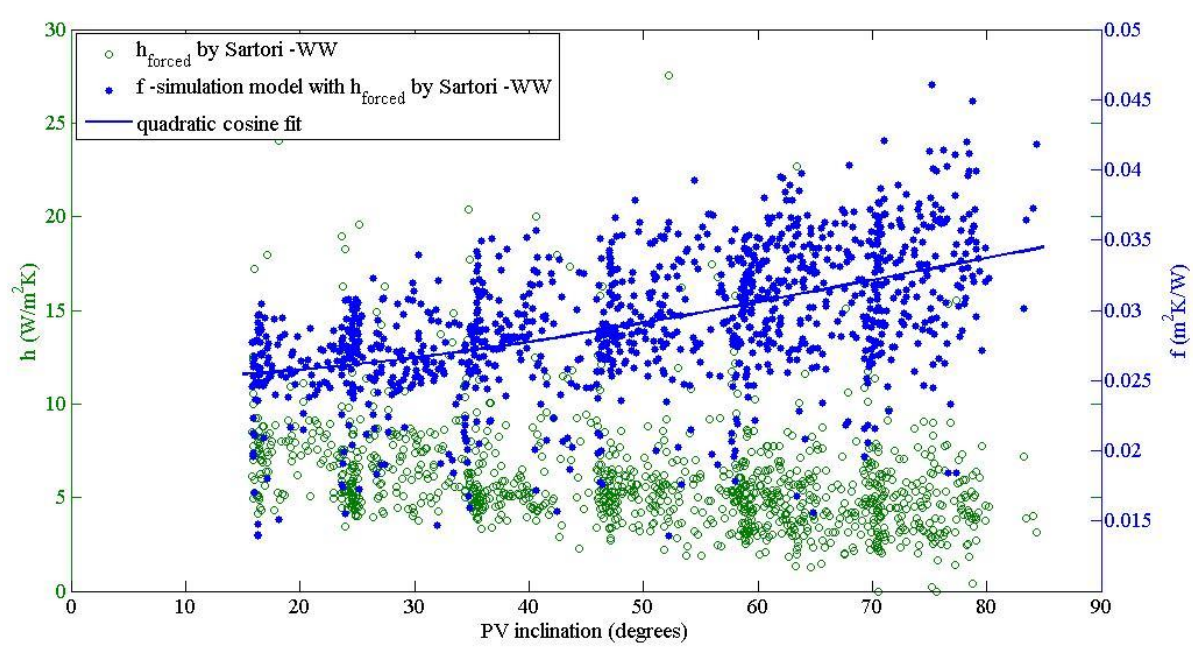

(b)

Fig.10. Forced convection coefficient and the $f$ coefficient provided by the simulation model in relation to PV inclination angle, using (a) Kendoush -WW and (b) Sartori -WW expressions. 
The experimental results of the $f$ coefficient which relates the intensity of solar radiation and ambient temperature to the PV module temperature, range mainly between $0.037 \mathrm{~m}^{2} \mathrm{~K} / \mathrm{W}$ for low wind velocities of about $1 \mathrm{~m} / \mathrm{s}$ to $0.012 \mathrm{~m}^{2} \mathrm{~K} / \mathrm{W}$ for high wind velocities of about 7-8 m/s. Fig.11 shows that in the experimental data at low to mid wind velocities, only a small increase in the $f$ takes place with increasing wind incidence angle. This effect becomes more pronounced at wind velocities above $5 \mathrm{~m} / \mathrm{s}$. On the other hand, the $f$ coefficient provided by the simulation model with $h$ for the windward side given by Kendoush expression and Sartori expressions for the various wind velocities and incidence angles, are displayed in Figs. 12a and 12b, respectively. Both approaches provide $f$ values close to the experimental for a wide range of wind velocities and wind incidence angles. However, small deviations occur particularly at high wind velocities and high wind incidence angles. At that range, the $f$ provided by the simulation model with $h$ determined using Kendoush expression exhibits a slight increase, while with $h$ using Sartori expression displays a slight decrease, compared to the experimental data.

The effect of PV inclination on the value of $f$ for the experimental data at various wind velocities is shown in Fig.13. A reduction in the value of $f$ is observed for increasing $\beta$ and particularly at PV inclination angles above $60^{\circ}$. The reduction is similar at the entire range of wind velocities. With respect to the effect of $\beta$ on the simulated value of $f$, both approaches using Kendoush and Sartori expressions exhibit similar characteristics, see Figs. 14a and 14b. At low to mid wind velocities the simulated $f$ value is increased with increasing PV inclination. This comes into contrast with the experimental data which show $f$ decreasing with $\mathrm{PV}$ inclination throughout the entire range of wind velocities. However, it should be noted that at very low wind velocities the effect of natural heat convection is comparable to the forced convection, and, thus, the increasing $f$ with increasing $\beta$ at very low wind velocities may be partly attributed also to the effect of natural heat convection. The effect of $\beta$ on $f$ is reversed with both approaches at wind velocities above $5 \mathrm{~m} / \mathrm{s}$, where $f$ decreases with increasing $\beta$. This comes to an agreement with the experimental data trend.

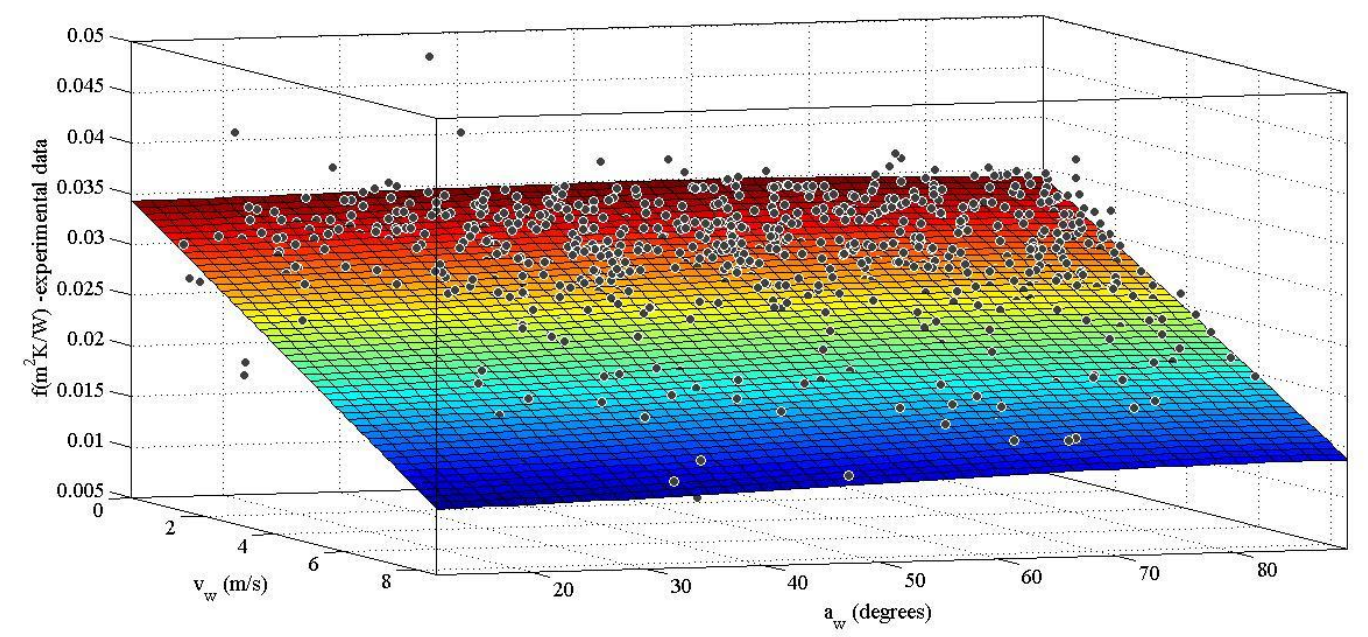

Fig.11. The $f$ coefficient determined from the experimental data in relation to wind velocity and wind incidence angle. 


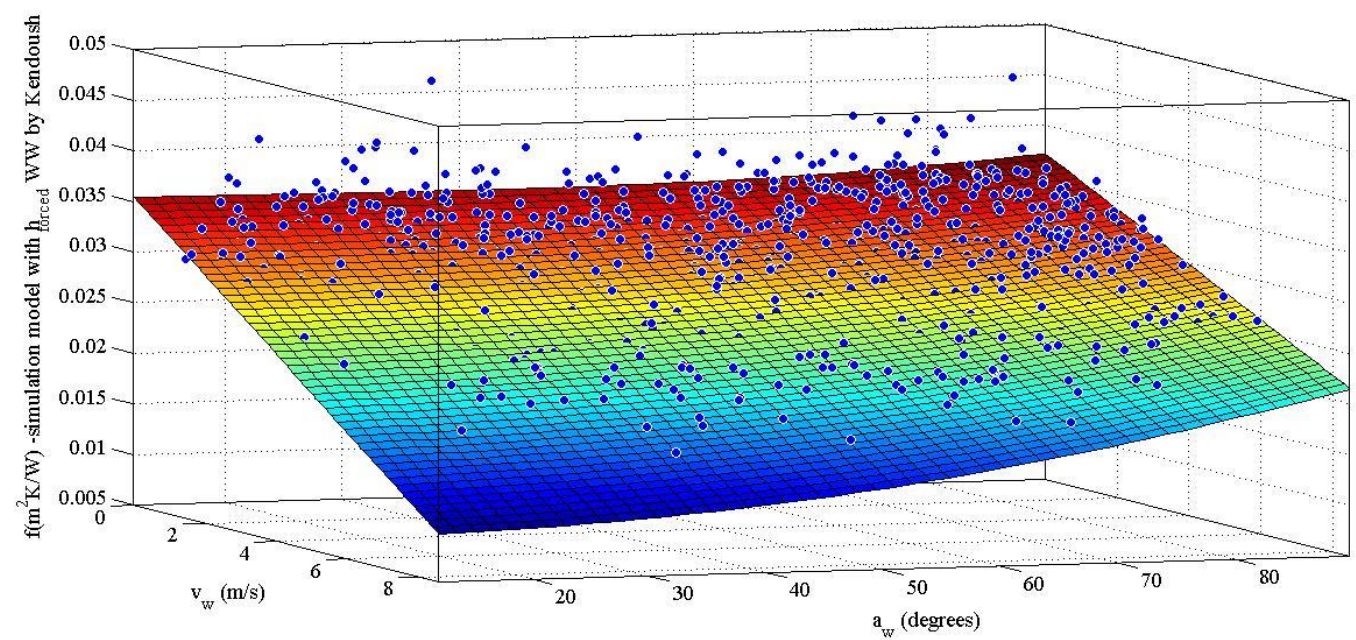

(a)

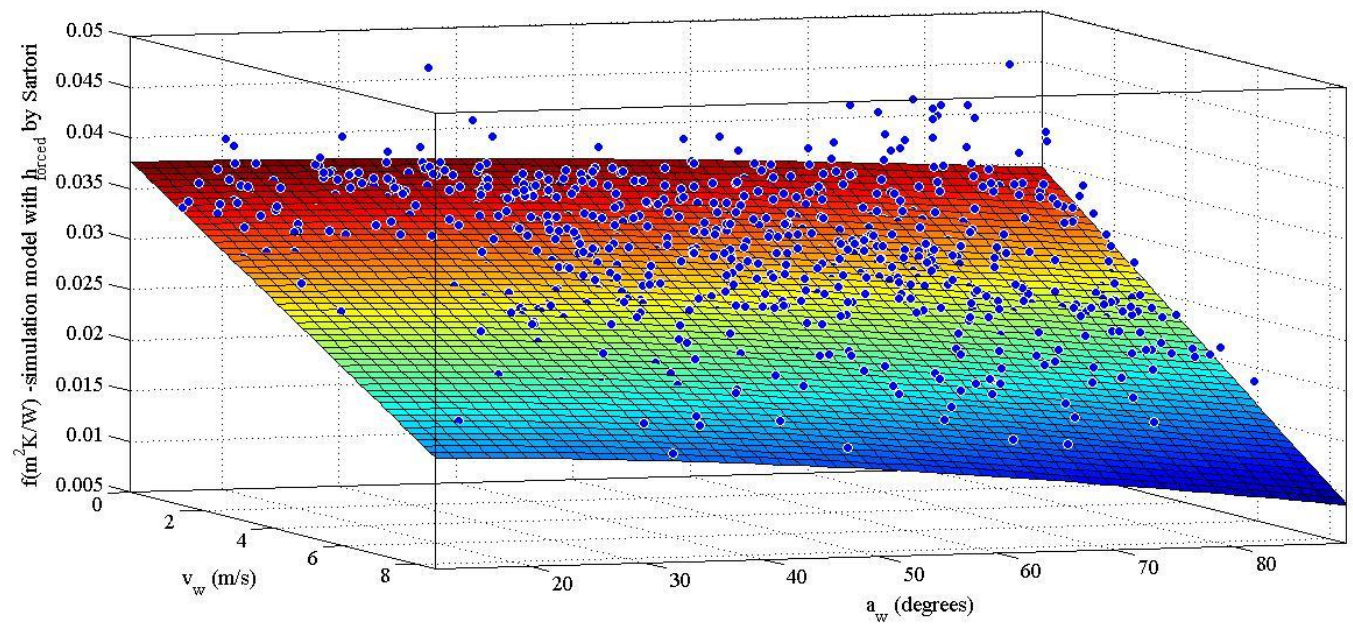

(b)

Fig.12. The $f$ coefficient provided by the simulation model in relation to wind velocity and wind incidence angle, using (a) Kendoush -WW and (b) Sartori -WW expressions for the forced convection coefficient .

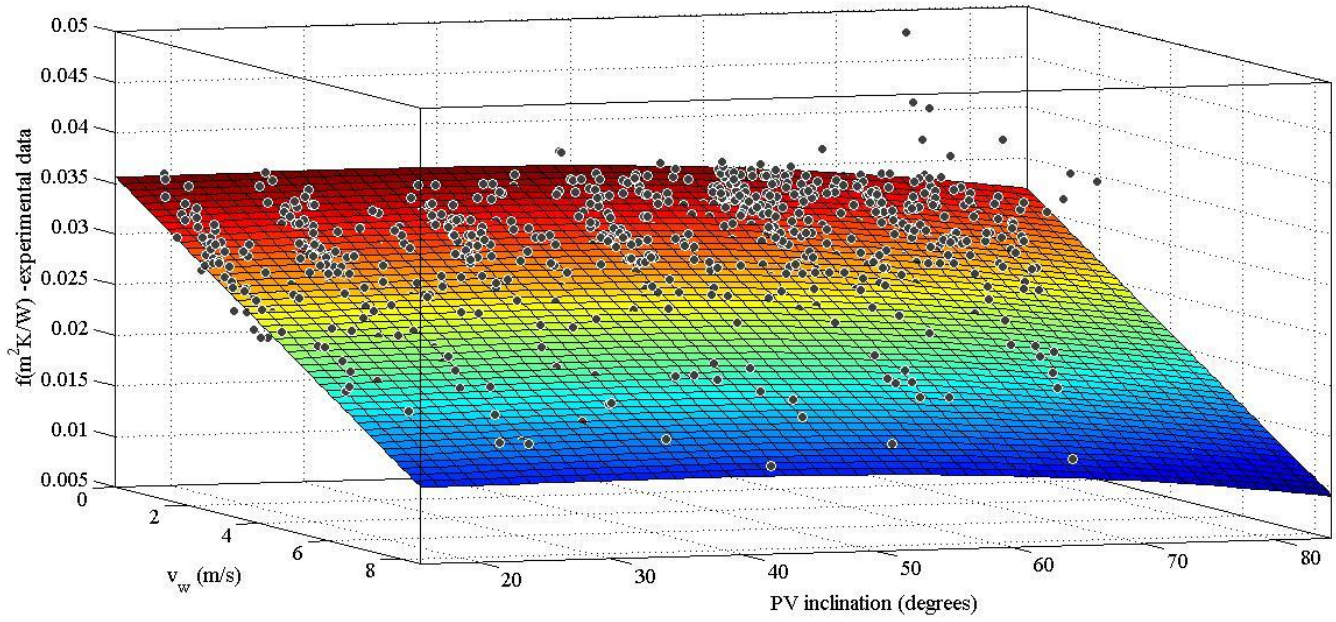

Fig.13. The $f$ coefficient determined from the experimental data in relation to wind velocity and PV inclination angle. 


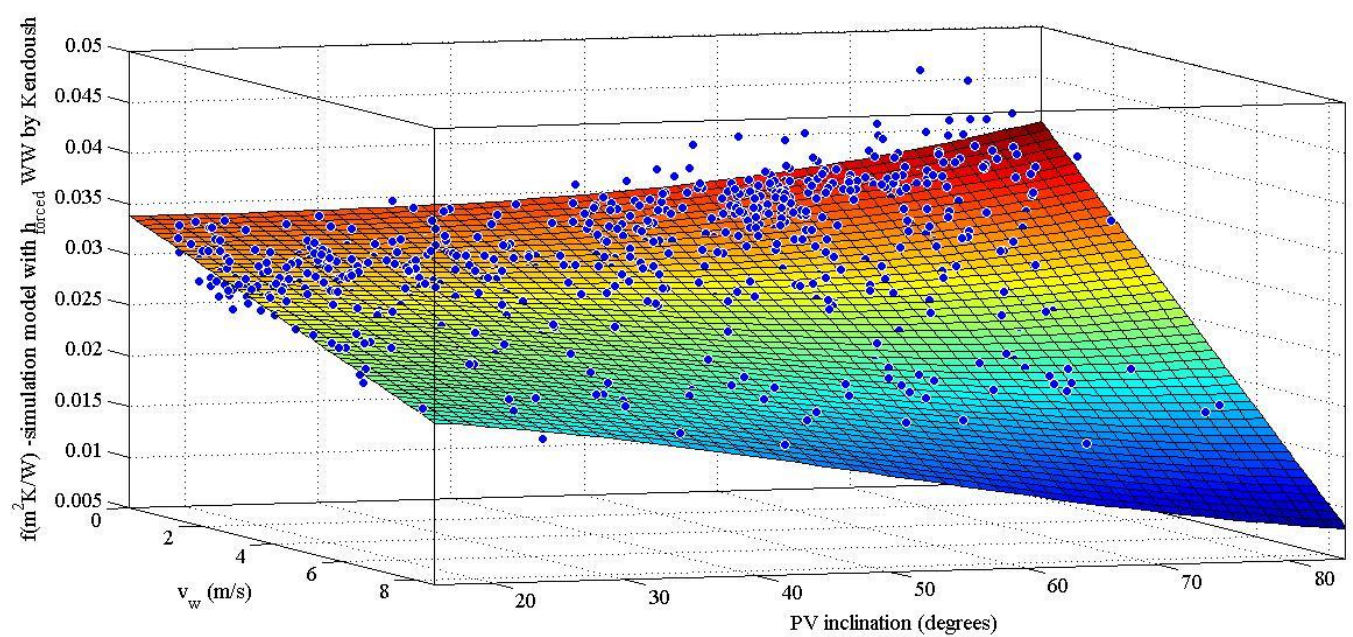

(a)

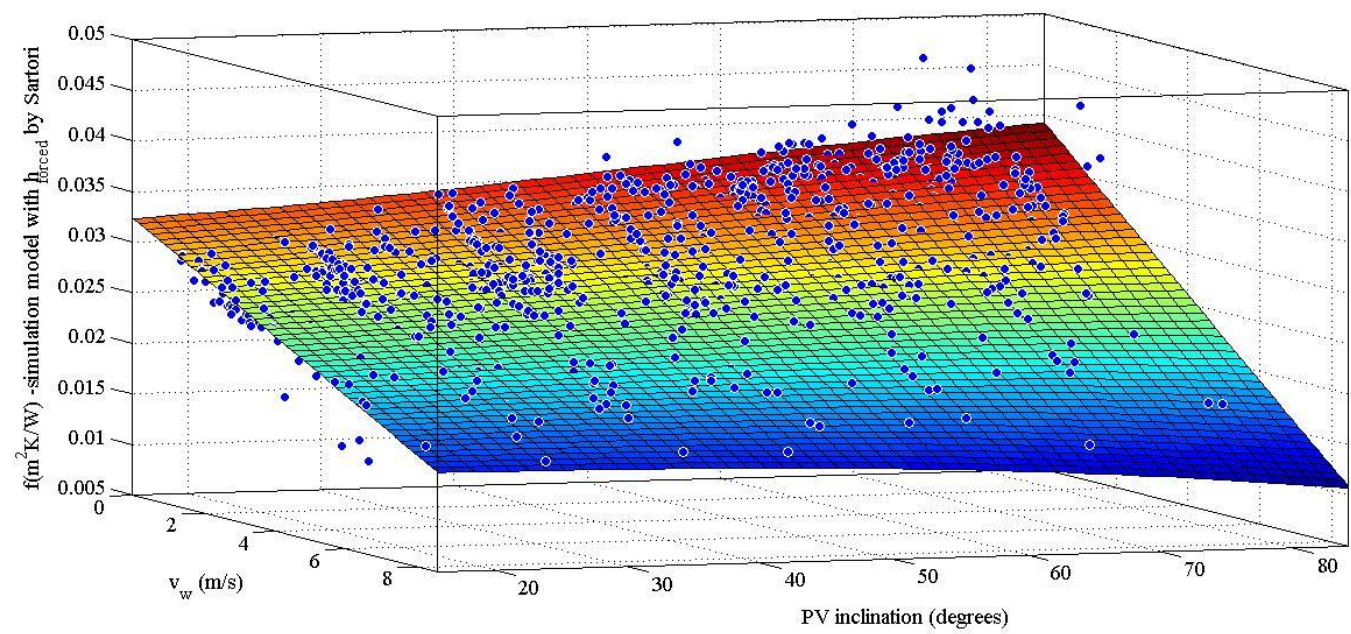

(b)

Fig.14. The $f$ coefficient provided by the simulation model in relation to wind velocity and PV inclination angle, using (a) Kendoush -WW and (b) Sartori -WW expressions for the forced convection coefficient.

\section{Discussion}

The simulation algorithm developed for the determination of the $f$ coefficient estimates all heat losses that occur during operation of a PV system outdoors. It was proven through experiment and simulation that the air forced convection coefficient, being related to the wind velocity and incidence angle, is very critical for the accurate determination of the overall heat losses. In fact, employing in the simulation algorithm two of the widely used empirical expressions that of Cole and Sturrock (1977), and Sharples and Charlesworth (1998) for the determination of the forced convection coefficient, led to $f$ values significantly deviating from the experimental data at the entire range of wind velocities (Fig. 7). This may be attributed to the fact that empirical equations are highly linked to the specific experimental conditions and equipment used for their derivation and, thus, may not be entirely fit at any conditions. The comparison of experimental and simulation results provided in this study highlight the clear benefit of using theoretical models. Two theoretical expressions for the forced convection coefficient, that of Kendoush (2009) and Sartori (2006), incorporating wind 
direction information, have been further explored and shown to provide $f$ values in good agreement with the experimental data. This gives additional evidence of the applicability of these theoretical models for the air forced convection coefficient in photovoltaic thermal analysis. In lack of an accompanying expression for the air forced convection coefficient at the leeward side of the module, in this simulation algorithm Sartori expressions were employed with the length $L$ estimated by $4 \mathrm{~A} / \mathrm{S}$, as encountered in (Sparrow et al., 1979), to account for heat convection through the entire area of the module. This approach for the leeward side gave satisfying results when used in combination with Kendoush, Sartori and Sparrow windward models, as shown in Figs. 4,5,7. Alternatively, an empirical equation $h=1.5 \cdot v_{w}+3$ for the leeward side was found in this study to provide a slightly better fit when used in combination with the Sartori and Kendoush expressions for the windward side. However, empirical models tend to optimise the result for the given experimental data.

A sensitivity analysis was performed for the assumption of $T_{p v, f}=T_{p v, b}$ in eq. (25). If the assumption is not made and a $\Delta T$ temperature difference exists between the back and the front PV surface, i.e. let $T_{p v, f}=T_{p v, b}-\Delta T$, then solving eq.(3) for $T_{p v, b}$ we get the above expression with $f$ coefficient now given by: $f=\left\lfloor\left((\tau \alpha)-\eta_{p v}\right)+U_{L, f} \Delta T / I_{T}\right\rfloor /\left(U_{L, f}+U_{L, b}\right)$. Thus, the effect of the additional term $U_{L, f} \Delta T / I_{T}$ on $f$ when running the simulation for all the experimental data of this study using different $T_{p v, f}$ and $T_{p v, b}$ gave a: $\frac{1}{f} \frac{\delta f}{\delta T} 100 \% \cong-2 \% /{ }^{\circ} \mathrm{C}$ (per degree difference between $T_{p v, f}$ and $T_{p v, b}$ ). As mentioned earlier, a 0 to $3^{\circ} \mathrm{C}$ temperature difference between the front glass and back Tedlar surface may typically be observed. Thus, for a temperature difference $\Delta T=3^{\circ} \mathrm{C}$, the average relative change in the $f$ coefficient was: $\frac{\delta f}{f} 100 \% \cong-6 \%$. Note that for $T_{p w, f}=T_{p v, b}+\Delta T$, then $\frac{\delta f}{f} 100 \% \cong 6 \%$. In this calculation different thermal properties of air for the front and back surface are used and thus natural convection as well as radiative heat transfer are affected by the difference in $T_{p v, f}$ and $T_{p v, b}$ However, this effect alone is very small, an average of $-0.6 \%$, compared to the effect of the additional term in the expression of $f$.

The importance of the $f$ coefficient in the prediction of $\mathrm{T}_{\mathrm{pv}}$ and, further, $\mathrm{P}_{\mathrm{m}}$ may be highlighted through the following example. Assuming the PV module of this study $\left(P_{m, s t c}=120 \mathrm{Wp}, \gamma_{\mathrm{Pm}}=-0.43 \% /{ }^{\circ} \mathrm{C}\right)$ operating outdoors under Standard Operating Conditions (SOC) $\left(I_{T}=800 \mathrm{~W} / \mathrm{m}^{2}, T_{a}=20^{\circ} \mathrm{C}, v_{w}=1 \mathrm{~m} / \mathrm{s}\right)$ and nominal operating cell temperature $\left(\mathrm{NOCT}=46.1^{\circ} \mathrm{C}\right.$ ) for $\mathrm{PV}$ at inclination $\beta=30^{\circ}$ oriented South $\left(\gamma_{p v}=180^{\circ}\right)$ and wind direction $\left(\gamma_{w}=140^{\circ}\right)$. This gives $\gamma=40^{\circ}$ and from eq. $(18): a_{w}=67.5^{\circ}$. The simulation model with $h$ given by Kendoush expression provides $f=0.0334$ and from eq. (26) $\mathrm{T}_{\mathrm{pv}}=46.72^{\circ} \mathrm{C}$ and, further, from eq.(1) the power output $\mathrm{P}_{\mathrm{m}}=84.678 \mathrm{~W}$. The simulation model with $h$ given by Sartori expressions provides $f=0.0336, \mathrm{~T}_{\mathrm{pv}}=46.88^{\circ} \mathrm{C}$ and $\mathrm{P}_{\mathrm{m}}=84.612 \mathrm{~W}$. For the same conditions and a wind velocity of $5 \mathrm{~m} / \mathrm{s}$, the simulation with $h$ given by Kendoush expression provides $f=0.0248, T_{\mathrm{pv}}=39.84^{\circ} \mathrm{C}$ and $\mathrm{P}_{\mathrm{m}}=87.518 \mathrm{~W}$, whereas with $h$ given by Sartori expressions provides $f=0.0243, \mathrm{~T}_{\mathrm{pv}}=39.44^{\circ} \mathrm{C}$ and $\mathrm{P}_{\mathrm{m}}=87.683 \mathrm{~W}$. Thus, as much as a $3.4 \%$ and a $3.6 \%$ increase in the peak power, respectively, is achieved by an increase in the wind velocity from 1 to $5 \mathrm{~m} / \mathrm{s}$. It is evident that $P_{m}$ is considerably affected by wind velocity through $\mathrm{T}_{\mathrm{pv}}$ and, thus, an accurate estimation of the $f$ coefficient may provide an accurate prediction of the power to be delivered. Note that in the above estimation of $\mathrm{P}_{\mathrm{m}}$ the $T_{p v}$ was used as derived from eq.(26) which corresponds to the temperature at the back of the module rather than the exact cell temperature. This leads to a small relative increase in the estimation of $\mathrm{P}_{\mathrm{m}}$ of about $1 \%$. This is derived using the expression of King et al. (2004) $T_{c e l l}=T_{p v, b}+\Delta T \cdot I_{T} / 1000$ for the estimation of the actual cell temperature, where $\Delta T$ is now the temperature difference between the cell and the back PV surface at $1000 \mathrm{~W} / \mathrm{m}^{2}$ and typically is 2 to $3^{\circ} \mathrm{C}$ for free standing modules. 
The simulation algorithm was developed for a double-axis sun-tracking PV system, a case of increasing interest in recent years where large PV plants are based on sun-trackers. Moreover, through the use of a sun-tracking rather than a fixed PV system, it was possible to have a wide range of PV inclination angles, orientations, and wind incidence angles on the PV plane, and study their effect on PV temperature. The PV inclination and orientation angle was estimated based on the sun position at the time of the recordings throughout the year. The wind incidence angle on the PV plane was estimated for any PV inclination, orientation and wind direction angle. The latter are input parameters in the algorithm. Evidently, the simulation model may also be applied straight forward to the simpler cases of a single-axis PV system, whereby depending on the axis of rotation one of the angles $\beta$ or $\gamma_{p v}$ is fixed, or to the case of a fixed PV system, whereby both angles $\beta$ and $\gamma_{p v}$ are constant. Note that in this study reflection losses were negligible as the angle of incidence of the solar irradiance on the PV plane was normal. For the cases of single-axis and fixed PV systems the reflection due to the angle of incidence of the incoming solar irradiance on the PV plane needs to be accounted for in the energy balance equation, i.e. the left side of eq.(3) should be changed to (1$r) \cdot(\tau \alpha) \cdot I_{T}$. An average reflectivity value of $10 \%$ has been used in (Bardhi, et al., 2012). In addition, in fixed PV systems care should be given in calculations that involve solar angle of incidence above 55 degrees, since in these cases additional optical losses occur as a result of the relative response of the PV module and mainly due to the reflectance characteristics of the glass with an estimated effect given in (King et al., 2004). Note that, the duration for which the solar angle of incidence is below 55 degrees, and, thus, these additional optical losses are negligible, corresponds to 2 to 3 hours around solar noon, i.e. to the largest part of the solar radiation during the day.

\section{Conclusions}

A theoretical and experimental comparative study for the evaluation of the $f$ coefficient relating the intensity of the global solar radiation on a PV plane and the PV temperature was presented. The experimental data covered a wide range of wind velocities, wind direction and PV inclination angles throughout a period of one year. The effect of wind velocity, wind incidence angle and PV inclination angle on the temperature of the PV module was examined in detail through their effect on the $f$ coefficient, in order to exclude the direct influence of solar irradiance and ambient temperature on PV temperature. The experimental results indicated that the $f$ coefficient takes values mainly between 0.037 and $0.012 \mathrm{~m}^{2} \mathrm{~K} / \mathrm{W}$ depending strongly on the wind velocity and also to the wind incidence angle. The experimentally estimated $f$ was shown to slightly increase with increasing wind incidence angle particularly at high wind velocities, implying that heat convection from the PV module is lower when the wind flows nearly in parallel to the PV surface. With respect to the effect of PV inclination on the $f$ coefficient, the experimental data gave a reduction in $f$ with increasing PV inclination angle at the entire wind velocity range.

A simulation model was developed for the determination of the $f$ coefficient through a detailed algorithm for the natural convection for the front and back PV side at any PV inclination, and for the forced convection, using theoretical expressions available in the literature. The determination of the forced convection coefficient for the windward and leeward side of the module incorporates information on the wind velocity, wind direction, PV inclination and orientation. Radiated heat exchanges between the PV module and the environment are included. The simulation algorithm, executed for the exact experimental conditions, solar radiation, ambient temperature, PV inclination, orientation, wind velocity and direction, provided the $f$ coefficient in close agreement to the experimentally estimated value throughout the entire range of external conditions tested. Both Kendoush and Sartori expressions for the forced convection coefficient provided results in close agreement to the experimental data. Although Kendoush expression depicts more accurately the 
effect of $a_{w}$ on $f$, as observed in the experimental data, milder discrepancies are encountered with Sartori expressions. The results suggest that any of the two models provide a good estimation of $f$.

The simulation model presented for the determination of the $f$ coefficient may finally serve the prediction of PV temperature for any PV system operating in free environment, under any inclination, orientation, wind direction and a wide range of wind velocity profiles. Thus, PV temperature may be predicted based on the basic meteorological parameters $\left(T_{a}, I_{T}, V_{w}, V_{w}\right)$. This may further serve the prediction of PV power output affected by $I_{T}$ and $T_{p v}$ according to eq.(1). Furthermore, it may serve the online load management for SAPV systems, the management of the grid for grid-connected PV systems, and through the use of weather forecast data this simulation could serve the PV power forecasting.

Further practical benefits of the model presented lie within the frame of a complete simulation of PV system performance throughout the year, based on the meteorological parameters at the site, and the predicted PV temperature, so as to serve the determination of the optimum PV inclination angle in fixed PV systems. This may be determined based on the maximum annual energy yield, as an optimum compromise between maximum incident solar radiation and minimum average PV temperature (minimum average $f$ coefficient), and, thus, lead to a reduction in the Pay Back Period.

Future work will be directed in such PV temperature prediction profiles along the year. The cases of cloudy weather conditions whereby solar radiation may exhibit significant fluctuations during small periods, will be examined in further work through a non-steady state model where heat transfer by conduction will be also included.

\section{References}

Amy de la Breteque, E., 2008. Thermal aspects of c-Si photovoltaic module energy rating, Solar Energy, 83, 1425-1433.

Anderson, A.J., 1996. Photovoltaic translation equations: A new approach, Final Subcontract Report, NREL/TP-411-20279.

Armstrong, S., Hurley, W.G., 2010. A thermal model for photovoltaic panels under varying atmospheric conditions, Applied Thermal Engineering, 30, 1488-1495.

Bardhi, M., Grandi, G., Tina, G.M., 2012. Comparison of PV cell temperature estimation by different thermal power exchange calculation methods. Int. Conf. on Renewable Energies and Power Quality (ICREPQ'12), 28-30 March, Santiago de Compostela, Spain.

Churchill, S.W., 1977. A comprehensive correlating equation for laminar, assisting, forced and free convection, AIChE Journal, 23(1), 10-16.

Churchill, S.W., Chu, H.H.S., 1975. Correlating equations for laminar and turbulent free convection from a vertical plate, Int. J. Heat Mass Transfer, 18, 1323-1329.

Cole, R.J., Sturrock, N.S., 1977. The convective heat exchange at the external surface of buildings, Building and Environment, 12, 207-214.

Duffie, J.A., Beckman, W.A., 1980. Solar engineering of thermal processes, John Wiley \& Sons, New York.

Faiman, D., 2008. Assessing the outdoor operating temperature of photovoltaic modules. Progress in Photovoltaics: Research and Applications, 16, 307-315.

Fujii, T., Imura, H., 1972. Natural-convection heat transfer from a plate with arbitrary inclination, Int. J. Heat Mass Transfer, 15, 755-767.

Incropera, F.P., DeWitt, D.P., 1996. Introduction to Heat Transfer, third ed., John Wiley \& Sons, New York.

Jones, A.D., Underwood, C.P., 2001. A thermal model for photovoltaic systems, Solar Energy, 70(4), 349-359. 
Justus, C.G., Mikhail, A., 1976. Height variation of wind speed and wind distributions statistics. Geophysical Research Letters, 3(5),261-264.

Kaplani, E., 2012. Detection of degradation effects in field-aged c-Si solar cells through IR thermography and digital image processing. International Journal of Photoenergy, Vol. 2012, Article ID 396792, pp.1-11. doi:10.1155/2012/396792.

Kaplani, E., Kaplanis, S., 2012. Temperature distribution effects in PV modules operating in field conditions. Proc. $5^{\text {th }}$ Int. Conf. on Sustainable Energy \& Environmental Protection (SEEP 2012), 5-8 June, Dublin, pp.256-261.

Kaplanis, S., Kaplani, E., Wolf, P., 2008. On the effect of the PV array inclination to its performance and efficiency. Proc. World Conf. WRECX, 19-25 July, Glasgow, UK.

Kendoush, A.A., 2009. Theoretical analysis of heat and mass transfer to fluids flowing across a flat plate, International Journal of Thermal Sciences, 48, 188-194.

King, D.L., 1996. Photovoltaic module and array performance characterization methods for all system operating conditions. Proc. of AIP Conference, 18-22 Nov. 1996, Colorado, USA, Vol. 394, 347368.

King, D.L., Boyson, W.E., Kratochvil, J.A., 2004. Photovoltaic array performance model, SANDIA Report, SAND2004-3535, Sandia National Laboratories, New Mexico.

King, D.L., Kratochvil, J.A., Boyson, W.E., 1997. Temperature coefficients for PV modules and arrays: Measurement, methods, difficulties, and results, Proc. 26th IEEE Photovoltaic Specialists Conf., Sept.29-Oct.3, Anaheim, California.

Koehl, M., Heck, M., Wiesmeier, S., Wirth, J., 2011. Modeling of the nominal operating cell temperature based on outdoor weathering, Solar Energy Materials \& Solar Cells, 95, 16381646.

Lunde, P. J., 1980. Solar thermal engineering. John Wiley and Sons, New York.

Mattei, M., Notton, G., Cristofari, C., Muselli, M., Poggi, P., 2006. Calculation of the polycrystalline PV module temperature using a simple method of energy balance, Renewable Energy, 31, 553567.

McAdams, W.H., 1954. Heat Transmission, third ed. McGraw-Hill, New York.

Notton, G., Cristofari, C., Mattei, M., Poggi, P., 2005. Modelling of a double-glass photovoltaic module using finite differences, Applied Thermal Engineering, 25, 2854-2877.

Palyvos, J.A., 2008. A survey of wind convection coefficient correlations for building envelope energy systems' modeling, Applied Thermal Engineering, 28, 801-808.

Radziemska, E., 2003. Thermal performance of $\mathrm{Si}$ and GaAs based solar cells and modules: a review. Progress in Energy and Combustion Science, 29, 407-424.

Sartori, E., 2006. Convection coefficient equations for forced air flow over flat surfaces, Solar Energy, 80, 1063-1071.

Sharples, S., Charlesworth, P.S., 1998. Full-scale measurements of wind-induced convective heat transfer from a roof-mounted flat plate solar collector. Solar Energy, 62(2), 69-77.

Skoplaki, E., Boudouvis, A.G., Palyvos, J.A., 2008. A simple correlation for the operating temperature of photovoltaic modules of arbitrary mounting. Solar Energy Materials \& Solar Cells, 92, 13931402.

Sparrow, E.M., Nelson, J.S., Tao, W.Q., 1982. Effect of leeward orientation, adiabatic framing surfaces, and eaves on solar-collector-related heat transfer coefficients, Solar Energy, 29(1), 33-41.

Sparrow, E.M., Ramsey, J.W., Mass, E.A., 1979. Effect of finite width on heat transfer and fluid flow about an inclined rectangular plate. Trans. ASME, Journal of Heat Transfer, 101, 199-204.

Tina, G., 2010. A coupled electrical and thermal model for photovoltaic modules, Journal of Solar Energy Engineering, 132, 1-5. doi: 10.1115/1.4001149.

Watmuff, J.H., Charters, W.W.S., Proctor, D., 1977. Solar and wind induced external coefficients Solar Collectors. Revue Internationale d'Heliotechnique, 2nd Quarter, pp.56.

White, F.M., 1988. Heat and Mass Transfer, Addison-Wesley Publishing, USA. 